\title{
H-Infinity Control of an Adaptive Hybrid Active Power Filter for Power Quality Compensation
}

\author{
Luc Vivien Assiene Mouodo' ${ }^{1}$, Jean Gaston Tamba ${ }^{2}$, Olivier Sosso Mayi ${ }^{3}$, Lawren Bibaya ${ }^{3,4}$ \\ ${ }^{1}$ Laboratory of Modeling Materials and Methods of the National Higher Polytechnic School, Douala University, Douala, Cameroon \\ ${ }^{2}$ Institute of Technology, Douala University, Douala, Cameroon \\ ${ }^{3}$ Higher Normal School of Technical Education, Douala University, Douala, Cameroon \\ ${ }^{4}$ School of Electrical and Electronic, Engineering University, Beijing, China \\ Email: assienemouodolucvivien@yahoo.fr
}

How to cite this paper: Mouodo, L.V.A., Tamba, J.G. Mayi, O.S. and Bibaya, L. (2020) H-Infinity Control of an Adaptive Hybrid Active Power Filter for Power Quality Compensation. Energy and Power Engineering, $12,603-640$.

https://doi.org/10.4236/epe.2020.1211037

Received: September 3, 2020

Accepted: November 9, 2020

Published: November 12, 2020

Copyright $\odot 2020$ by author(s) and Scientific Research Publishing Inc. This work is licensed under the Creative Commons Attribution International License (CC BY 4.0).

http://creativecommons.org/licenses/by/4.0/

\section{(c) (i) Open Access}

\begin{abstract}
This article highlights an optimal robust control technique called H-infinity, which thanks to a particular algorithm offers several solutions in the experimental implementation of harmonic compensators of systems with API-siemens modules. This control and command technique is directly tested on a TLC adaptive hybrid filter topology that provides benefits, such as reduced switching losses when injecting currents in the network, limitation of resonance problems and above all low power consumption at the DC bus level, thus allowing us to obtain results for $105 \mathrm{~V}$ to be compared with existing models in the literature which require $600 \mathrm{~V}$ for the same performance. This article therefore simultaneously offers two essential contributions to the optimization of harmonic pollution control. A first contribution is essentially based on the $\mathrm{H}$-infinite algorithm and its particularity in its implementation on our TLC hybrid model. The second is on the advantages offered by the TLC-HAPF hybrid topology. The results obtained with this algorithm give us THDs conforming to the IEEE 519-1996 and which are very meaningful compared to the results obtained with other robust and stochastic control algorithms taken under the same conditions.
\end{abstract}

\section{Keywords}

H-Infinity Algorithm Control, TCLC-HAPF, THD, Depollution

\section{Introduction}

Electrical energy is the most efficient and popular form of energy and the mod- 
ern society is heavily dependent on the electric supply. The life cannot be imagined without the supply of electricity. At the same time, the quality of the electric power supplied is also very important for the efficient functioning of the end user equipment. The term power quality became most prominent in the power sector and both the electric power supply company and the end users are concerned about it [1]. The quality of power delivered to the consumers depends on the voltage and frequency ranges of the power. If there is any deviation in the voltage and frequency of the electric power delivered from that of the standard values, then the quality of power delivered is affected. Nowadays with the advancement in technology, there is a drastic improvement in the semi-conductor devices. With this development and advantages, the semi-conductor devices got a permanent place in the power sector helping to ease the control of overall system. Moreover, most of the loads are also semi-conductor based equipment. But the semi-conductor devices are non-linear in nature and draw non-linear current from the source. And also the semi-conductor devices are involved in power conversion, which is either AC to DC or from DC to AC. This power conversion contains a lot of switching operations which may introduce discontinuity in the current. Due to this discontinuity and non-linearity, harmonics are present which affect the quality of power delivered to the end user. In order to maintain the quality of power delivered, the harmonics should be filtered out. Thus, a device named Filter is used which serves this purpose. There are many filter topologies in the literature, like active, passive and hybrid. Installation of the current quality compensators is one of the solutions for the low power factor, harmonic current pollution and unbalanced problem. Different power quality compensators have been compared in historical order in the following: Shunt capacitor banks (CBs) were firstly applied in power systems in around 1900s for power-factor correction and feeder voltage control due to its advantages of low cost and flexibility of installation. However, CBs can easily get burnt if the current harmonics level is high. To compensate the current harmonics, the passive power filters (PPFs) were proposed in 1940s. Unfortunately, the PPFs have many disadvantages, such as low dynamic performance, resonance problem and lack of unbalanced compensation ability [2]. The thyristor controlled static var compensators (SVCs) were firstly proposed in 1960s [3]. And the SVCs are popularly for dynamic reactive power [4] [5] [6] [7] and unbalanced power compensations [8] [9] [10]. However, the SVCs suffer from drawbacks, such as resonance problem, harmonic current injection and poor harmonic compensation ability. To overcome the drawbacks and improve the performances of SVCs simultaneously, the inverter based controlled active power filters (APFs) were proposed in the year of 1976 [11] [12]. Unfortunately, APFs still cannot have large scale development in the power quality markets due to the high initial and operational costs. Afterwards, the LC-coupling hybrid active filters (HAPFs) were proposed in the year of 2003. And, HAPFs have lower rating of active inverter part than the APFs. Since the rating of active inverter part is proportional to the cost of 
compensators, the HAPFs are more cost-effective than the APFs [13]-[18]. However, the HAPFs have a quite narrow compensation range, which limits its compensation ability. When the loading reactive power is outside its designed range, it loses its low-inverter rating advantages [19]. In the year of 2014, the topology of thyristor controlled LC coupling hybrid active power filter (TCLC-HAPF) is proposed in [20], in which this state-of-the-art TCLC-HAPF has the characteristics of a wider compensation range than HAPFs and lower dc-link voltage than APFs for power quality compensation. Until now, the complete studies of characteristics, design techniques and applications of the TCLC-HAPF are still lacking to enhance the characteristics of passive filter and also the system; the active filter should be controlled properly. There are different control techniques for this purpose. The main aim of any control technique is to make active filter inject a voltage in to the system that compensates the harmonics. To achieve this output voltage, the active filter is controlled such that it is equal to a pre-calculated reference value. In this paper the proposed theory is validated by simulating it in MATLAB SIMULINK environment. The proposed control strategy is simulated for both balance and unbalanced load conditions. In this project the use of H-Infinity to control hybrid adaptive power filters for the improvement of electric power quality is studied and analyzed.

\section{Research Motivation}

\subsection{Solutions to Power Quality Problems}

The most effective solution to improve the power quality is the use of filters to reduce harmonics. The basic idea of using a filter is explained in Figure 1, where the filter injects a compensating current that compensates the harmonics in load current. There are different filter topologies in the literature such as- active, passive,

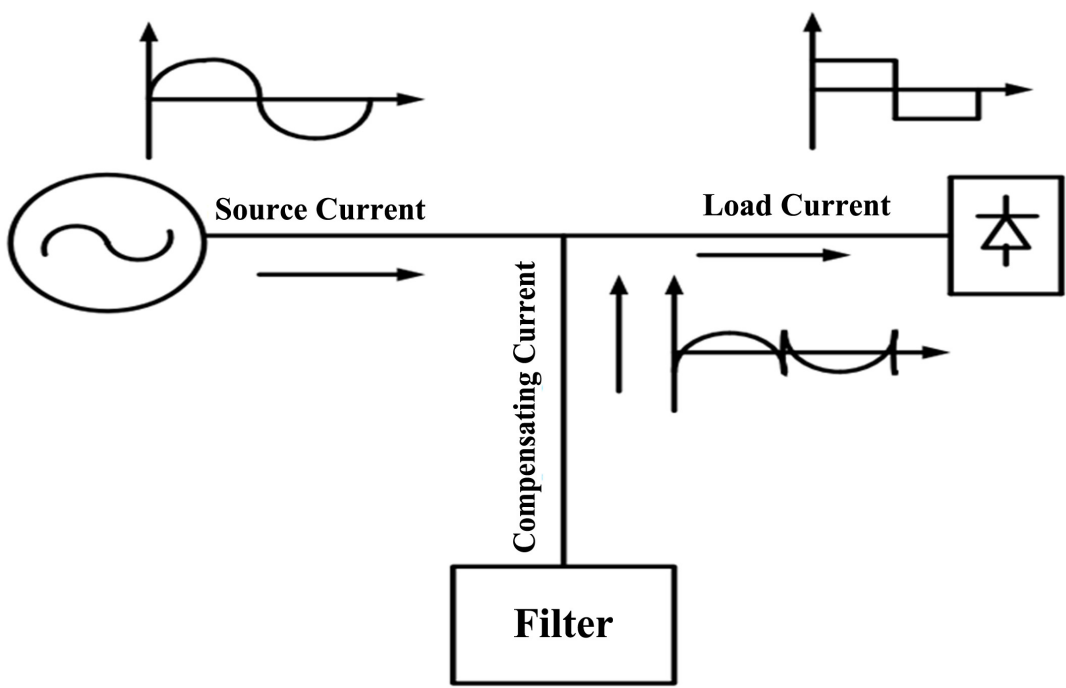

Figure 1. Basic filter topology. 
hybrid, TCLC-HAPF. The passive power filters are used to filter out a particular order harmonics and has the problem of parallel resonance. The other solution is the use of Active Power Filter (APF). There are different types of APF like series APF, shunt APF. The shunt APF is costly and is not used for large systems. The series APF works as a harmonic isolator and used to reduce the negative sequence voltage [2]. The combination of passive filter and APF known as Hybrid Filter has also been study but has a narrow compensation range. There is another filter topology which is the TCLC-HAPF which is study in this project.

\subsection{Objectives}

The main objective of this project is to control the thyristor controlled LC coupling hybrid active power filter (TCLC-HAPF) such that the harmonics in the current waveform are reduced. The control algorithm has the following objectives:

$>$ To control the voltage injected by TCLC-HAPF such that it compensates the reactive power and load current harmonics

$>$ To improve the passive filter performance

$>$ To make the whole compensating equipment to act as linear, balanced, resistive load on the system

\subsection{Filter Classification}

The different filters present in the literature are classified into three basic types. They are Active Filters and Passive Filters and Hybrid filter. Each type has its own sub classification. Figure 2 shows the detailed classification of the filters.

\subsection{Comparisons among Thyristor Controlled LC-Coupling Hybrid Active Power Filter (TCLC-HAPF) and Other Different Power Quality Filters}

Installation of the current quality compensators is one of the solutions for different power quality problems such as the low power factor, harmonic current pollution and unbalanced problem. The historical review of different power

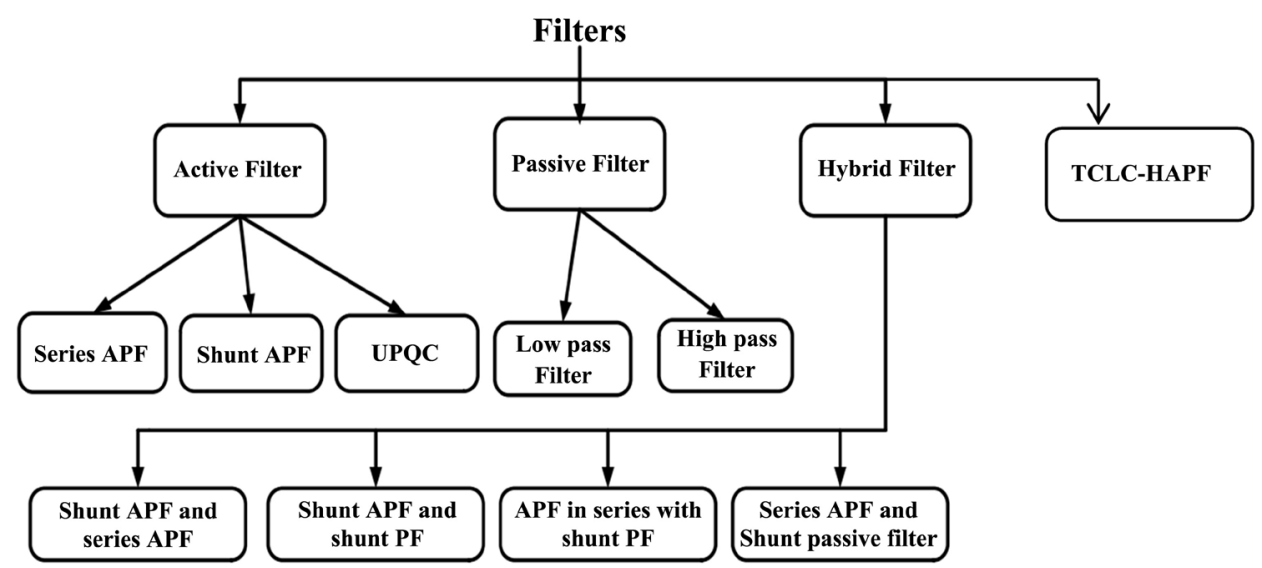

Figure 2. Filter classification. 
quality compensators are summarized in Table 1 and compared in the following. To compensate the reactive power, current harmonics, the passive power filters (PPFs) were proposed in 1940s. Unfortunately, the PPFs have many disadvantages like poor dynamic performance, resonance problem, and fixed reactive power compensation [1] [2]. The static var compensators (SVCs) were firstly proposed in 1960s. And, the SVCs are popularly used for dynamic reactive power compensation [3]. However, the SVCs still suffer drawbacks such as resonance problem, harmonic.

Current injection and poor harmonic compensation ability. To overcome those drawbacks of SVCs and provide better performances simultaneously, the active power filters (APFs) were proposed in the year of 1976 [4] [5] [6]. Unfortunately, APFs still cannot large scale development in the power quality markets due to the high initial and operational costs. Afterwards, the LC-coupling hybrid active filters (HAPFs) were proposed in the year of 2003 with low active inverter part rating [7] [8] [9]. Since the rating of the active inverter part is proportional to the cost of compensators, the HAPFs are more cost effective than the APFs. However, the HAPFs have a quite narrow compensation range, which limits its compensation ability. When the load reactive power is outside its designed range, it loses its low-inverter rating advantages. From 2014 onwards, the thyristor controlled LC coupling hybrid active power filters (TCLC-HAPFs) have been widely studied in [10]-[16], which have the desirable characteristics of a wider compensation range than HAPFs and lower dc-link voltage than APFs for power quality compensation. Based on above discussions and Table 1, the traditional power quality compensators, PPFs and SVCs have inherent problems like resonance problem, slow response, poor harmonic compensation ability, etc. The above mentioned inherent problems can be solved if the active inverter part has been added to the topologies such as APFs, HAPFs and TCLC-HAPFs. However, the cost of PPF and SVC are lower than that of the active inverter part, thus the reduction of the active inverter part rating can lead to a decrease in the total cost of APFs, HAPFs and TCLC-HAPFs. After serious compariation the conclution was drawn, the comparisons among the APF, HAPF and TCLC-HAPF have been provided in terms of $\mathrm{V}$-I characteristic (compensation range and

Table 1. Characteristics of different active current quality compensators [4].

\begin{tabular}{cccccc}
\hline Year & 1940s & 1960s & 1976 & 2003 & 2014 \\
\hline compensators & PPFs & SVCs & APFs & HAPFs & TCLC-HAPFs \\
Compensation range & Narrow & Wide & Wide & Narrow & Wide \\
Harmonics compensation & Normal & Poor & Good & Good & Good \\
Cost & Lowest & Low & High & Normal & Normal \\
reliability & high & High & Low & Normal & Normal \\
Switching loss & Low & Low & high & Normal & Normal \\
Tracking performance & poor & Poor & Good & Poor & Good \\
\hline
\end{tabular}


require DC-link voltage) cost, reliability, power loss and tracking performance. Compared TCLC-HAPF with APF and HAPF, it has higher reliability and lower power loss than both APF and HAPF. Besides, the TCLC-HAPF can be more cost effective than the APF for medium/high voltage level applications $(\geq 10 \mathrm{kV})$. In addition, the TCLC-HAPF has wider reactive current compensation range than the HAPF and lower DC-link voltage than the HAPF. Therefore, the TCLC-HAPF has a large potential to be further developed for medium/high voltage level applications.

\section{The Circuit Configuration and Modeling of the Three-Phase TCLC-HAPF}

The circuit topology of a three-phase three-wire TCLC-HAPF is provided in Figure 3. $v_{s x}$ and $v_{\text {invx }}$ are the source voltages, load voltage and inverter output voltage, respectively, where the subscript " $x$ " denotes phase $x=a, b, c, i_{s x} i_{L X}$ and $i_{c x}$ are source current, load current and compensating current, respectively. The TCLC part of the TCLC-HAPF consists of a coupling inductor $L_{\mathcal{O}}$ a parallel capacitive CPF and a thyristor controlled reactor (TCR) with an inductor LPF. The active inverter part is a two-level voltage source inverter (VSI) with a dc-link capacitor CDC. The active inverter part can be considered as the adjustable active impedance to improve the TCLC part fundamental and harmonic current compensation ability [21] [22]. Therefore, the three-phase modeling is proposed in Figure 3 for TCLC-HAPF compensation analysis.

The equivalent compensating circuit is shown in Figure 3.

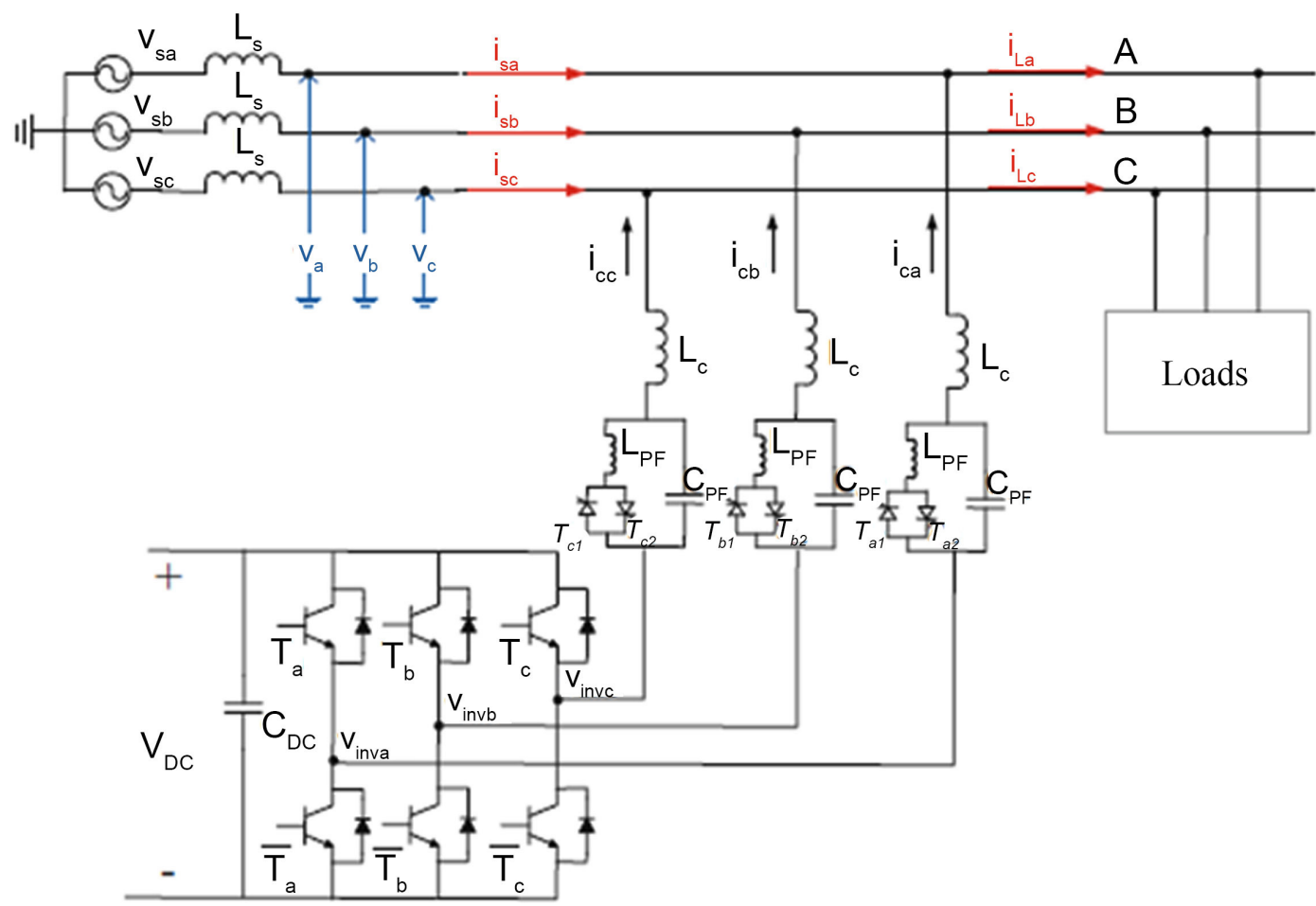

Figure 3. TLC adaptive hybrid filter topology. 
The active inverter part can be considered as the adjustable active impedance to improve the TCLC part fundamental and harmonic current compensation ability [20] and [21]. Therefore, the three-phase modeling for TCLC-HAPF unbalanced compensation analysis is proposed in Figure $4 \&$ Figure 5 . At the fundamental frequency (Figure 4), the active impedance $X_{A C T x f}$ is used to help the TCLC part impedance $X_{a f}$ to compensate fundamental reactive power and balance active power. At the harmonic frequency (Figure 5), the active impedance $X_{A C T x n}$ changes the equivalent TCLC-HAPF impedance to be zero, so that the load harmonic current will not pollute the source side. The fundamental and harmonic active impedance $X_{A C T X f}$ and $X_{A C T X n}$ are proportional to the inverter voltage. To keep active inverter working at low rating, the $X_{A C T X f}$ and $X_{A C T \times n}$ need to be designed as small as possible.

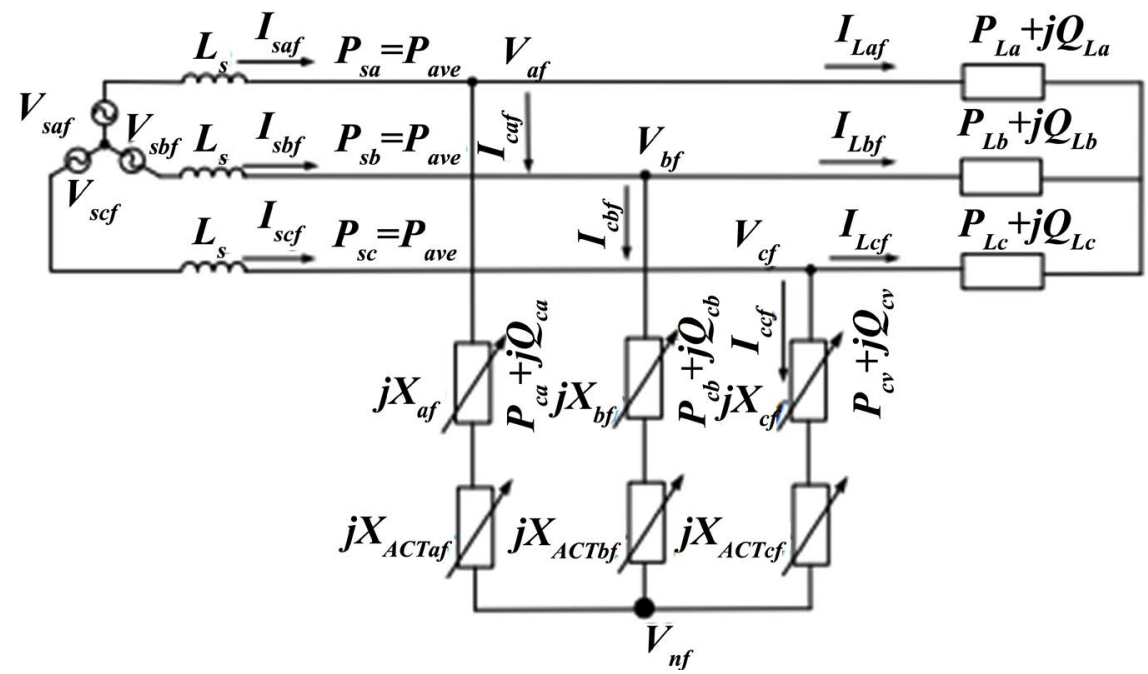

Figure 4. The three-phase TCLC-HAPF modeling for compensation at fundamental frequency.

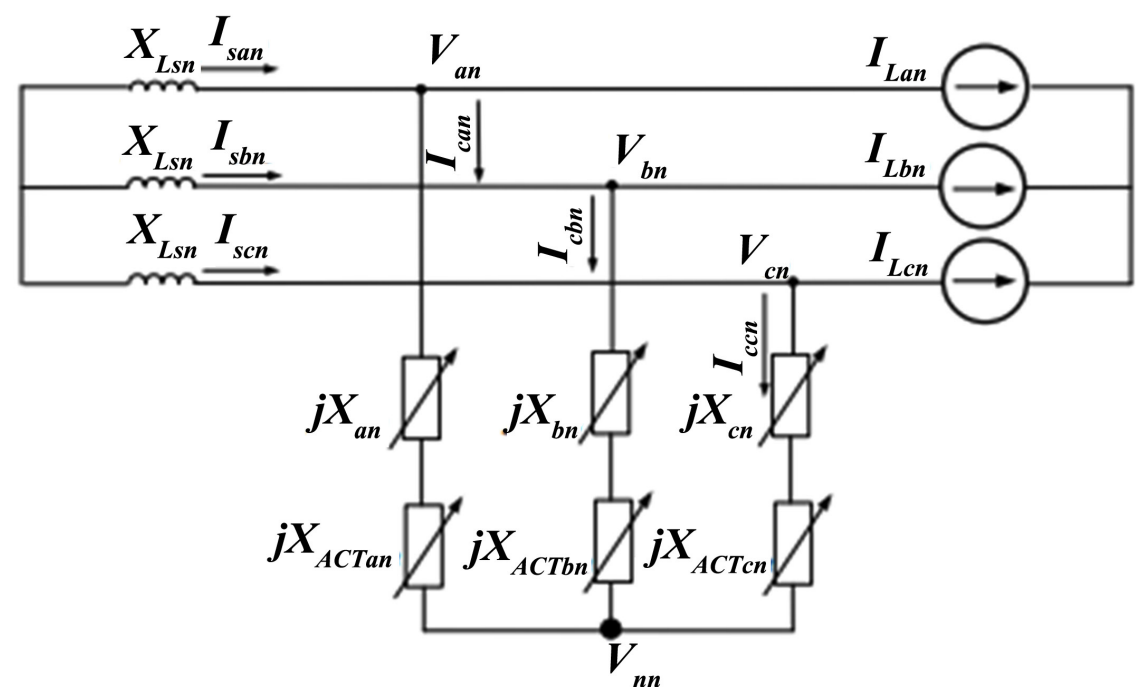

Figure 5. The three-phase TCLC-HAPF modeling for compensation at harmonic frequency. 


\subsection{Proposed TCLC-HAPF Parameter Design}

In this section, a parameter design method is discussed and explained into three parts. In Part A, the relationship between the required TCLC-HAPF fundamental impedances $\left(X_{a f}+X_{A C T X}\right)$ and the load powers is deduced based on power flow analysis. The parameter design of the required fundamental dc-link voltage $V_{D C} C_{P F}$ and $L_{P F}$ is proposed under the fundamental frequency consideration. In Part B, the parameter design of the required harmonic dc-link voltage $V_{D C h}$ is proposed under harmonic frequency consideration. In Part C, the design of $L_{c}$ is given.

\subsection{Design of $V_{d c f}, C_{P F}$ and $L_{P F}$ Based on Power Flow Analysis under Fundamental Frequency Consideration}

Referring to Figure 4, the required TCLC-HAPF impedance $\left(X_{x f}+X_{A C T x f}\right)$ can be calculated by applying the Ohm's Law as:

$$
j X_{x f}+j X_{A C T x f}=\left(\vec{V}_{x f}-\vec{V}_{n f}\right) / \vec{I}_{c x f}
$$

where $V_{x f}$ and $I_{c x f}$ are the fundamental load voltage and compensating current phasors respectively, where $x$ stands for phase $a, b$ and $c . V_{n}$ is the fundamental common point voltage. By using the Kirchhoff s circuit laws (KCL), the compensating current relationship can be expressed as:

$$
\vec{I}_{c a f}+\vec{I}_{c b f}+\vec{I}_{c c f}=\frac{\vec{V}_{a}-\vec{V}_{n f}}{j X_{a f}+j X_{A C T a f}}+\frac{\vec{V}_{b}-\vec{V}_{n f}}{j X_{b f}+j X_{A C T b f}}+\frac{\vec{V}_{c}-\vec{V}_{n f}}{j X_{c f}+j X_{A C T c f}}=0
$$

Simplifying (2.2), the expression of $V_{n f}$ can be obtained as:

$$
\begin{aligned}
\vec{V}_{n f}= & \frac{\left(X_{b f}+X_{A C T b f}\right)\left(X_{c f}+X_{A C T c f}\right)}{X_{E Q f}} \cdot \vec{V}_{a f}+\frac{\left(X_{c f}+X_{A C T c f}\right)\left(X_{a f}+X_{A C T a f}\right)}{X_{E Q f}} \cdot \vec{V}_{b f} \\
& +\frac{\left(X_{a f}+X_{A C T a f}\right)\left(X_{b f}+X_{A C T b f}\right)}{X_{E Q f}} \cdot \vec{V}_{c f}
\end{aligned}
$$

where

$$
\begin{aligned}
X_{E Q f}= & \left(X_{a f}+X_{A C T a f}\right)\left(X_{b f}+X_{A C T b f}\right)+\left(X_{b f}+X_{A C T b f}\right)\left(X_{c f}+X_{A C T c f}\right) \\
& +\left(X_{c f}+X_{A C T c f}\right)\left(X_{a f}+X_{A C T a f}\right)
\end{aligned}
$$

The $I_{c x f}$ can be expressed in terms of $V_{f x}\left(V_{x}=V_{f x}\right.$ for $V_{x}$ is assumed to be pure sinusoidal without harmonic components [11]-[18] and the compensating active and reactive power $P_{c x}$ and $Q_{c x}$ as:

$$
\begin{gathered}
j X_{x f}+j X_{A C T x f}=\left(\vec{V}_{x f}-\vec{V}_{n f}\right) / \vec{I}_{c x f} \\
\vec{I}_{c x f}=\left[\left(P_{c x}+j Q_{c x}\right) / \vec{V}_{x}\right]^{*}
\end{gathered}
$$

where the note "*" denotes the conjugate. For unbalanced compensation, the TCLC-HAPF can provide the same amount of $Q_{c x}$ as the loading required but with opposite directions and balance the three-phase source active power to their average values $\left(P_{L a}+P_{L b}+P_{L c}\right) / 3$ simultaneously. Thus, the compensat- 
ing $P_{c x}$ and $Q_{c x}$ can be expressed as:

$$
Q_{c x}=-Q_{L x} \text { and } P_{c x}=-\left(P_{L x}-\frac{P_{L a}+P_{L b}+P_{L c}}{3}\right)
$$

Referring to Figure 2(a), the fundamental inverter voltage $V_{\text {invxf }}$ can be obtained as:

$$
V_{\text {invxf }}=X_{\text {ACTxf }} \cdot I_{c x f}
$$

where $X_{A C T X f}$ and $I_{c x f}$ are the fundamental active impedance and compensating current, and $I_{c x f}$ is design to compensate load fundamental reactive current $I_{L x f q}\left(I_{c x f}=-I_{L x f q}\right)$. The relationship between the $V_{i n v x f}$ and $V_{D C x f}$ can be expressed as:

$$
V_{D C x f}=\sqrt{6} \cdot V_{i n v x f}
$$

In (9), the scale of $\sqrt{6}(=\sqrt{2} \cdot \sqrt{3})$ can be explained by the following two reasons:

1) To transfer the phase voltage $V_{\text {invxf }}$ to line-to-line voltage, the scale of 3 is required,

2) To guarantee the sufficient $V_{D C x}$ the peak value of fundamental inverter voltage needs to be considered

$$
V_{\text {invof }}(p)=\sqrt{2} \cdot V_{\text {invxf }}
$$

Moreover, the final required $V_{D C f}$ is designed to be the maximum value among each phase. Therefore, the final required $V_{D C f}$ can be expressed as:

$$
V_{D C f}=\max \left(\sqrt{6} V_{\text {invaf }}, \sqrt{6} V_{\text {invbf }}, \sqrt{6} V_{\text {invcf }}\right)
$$

The $X_{A C T X f}$ is directly proportional to the required $V_{D C f}$ The low dc-link voltage is one of the major advantages of TCLC-HAPF. This can be achieved when the value of $X_{A C T X f}$ is designed to be zero $\left(X_{A C T X f} \approx 0\right)$. In other words, the value of $V_{D C f}$ is minimized ( $V_{D C f} \approx 0$ ). With such minimum $V_{D C f}$ design, the TCLC part is mainly used to compensate reactive power and balance the active power, while the active inverter part is mainly used to improve the harmonic compensation ability of TCLC part. The TCLC part is an $L_{c}\left(X_{L c}\right)$ in series with a paralleled combination of a $L_{P F}\left(X_{L P F}\right)$ and a $C_{P F}\left(X_{C P F}\right)$, in which the $X_{x f}$ can be deduced as:

$$
\left[\begin{array}{c}
X_{a f}\left(\alpha_{a}\right) \\
X_{b f}\left(\alpha_{b}\right) \\
X_{c f}\left(\alpha_{c}\right)
\end{array}\right]=\left[\begin{array}{c}
\frac{\pi X_{L_{P F}} X_{C_{P F}}}{X_{C_{P F}}\left(2 \pi-2 \alpha_{a}+\sin 2 \alpha_{a}\right)-\pi X_{L_{P F}}}+X_{L_{c}} \\
\frac{\pi X_{L_{P F}} X_{C_{P F}}}{X_{C_{P F}}\left(2 \pi-2 \alpha_{b}+\sin 2 \alpha_{b}\right)-\pi X_{L_{P F}}}+X_{L_{c}} \\
\frac{\pi X_{L_{P F}} X_{C_{P F}}}{X_{C_{P F}}\left(2 \pi-2 \alpha_{c}+\sin 2 \alpha_{c}\right)-\pi X_{L_{P F}}}+X_{L_{c}}
\end{array}\right]
$$

In (12), $X_{L \mathcal{C}}, X_{C P F}, X_{L P F}$ are the fundamental impedances of $L_{\mathcal{C}}, C_{P F}$ and $L_{P F} \alpha_{X}$ is the firing angle of the thyristor. The TCLC part has two back-to-back connected thyristors $\mathrm{T} 1 \mathrm{x}, \mathrm{T} 2 \mathrm{x}$, and they are triggered alternately in every half cycle. When $\alpha_{x}=180^{\circ}$ (thyristors are opened for the whole cycle), the TCLC part has the 
maximum capacitive impedance $X \operatorname{Cap}(\operatorname{Max})(<0)$. On the other hand, when the firing angle $\alpha_{x}=90^{\circ}$ (one of thyristors is closed for whole cycle), the TCLC part has the minimum inductive impedance XInd(Min) (>0). Therefore, XCap (Max) and $X I n d(M i n)$ can be expressed as:

$$
\begin{gathered}
X \operatorname{Xap}(\operatorname{Max})=X_{L C}-X_{C P F}=w L_{c}-\frac{1}{w C_{p F}} \\
X i n d(\operatorname{Min})=\frac{X_{L P F} X_{C P F}}{X_{C P F}-X_{L P F}}+X_{L c}=\frac{w L_{P F}}{1-C_{P F} W^{2} L_{P F}}+W L_{c}
\end{gathered}
$$

where $\omega(=2 \pi f)$ is the angular frequency. To guarantee the TCLC part has inductive compensation range and capacitive compensation range, the basic conditions of $X \operatorname{Cap}(\operatorname{Max})<0$ and $X I n d(\operatorname{Min})>0$ need to be satisfied. Thus, from (13) and (14), the following relationships can be obtained:

$$
C_{P F}<\frac{1}{L_{c} W^{2}} \text { and } L_{P F}<\frac{1}{C_{P F} W^{2}}
$$

\section{Control Strategy}

The TCLC-HAPF should be controlled such that the voltage injected by it should compensate the harmonics present in the system and should help in improving the quality of power. To achieve the above purpose, the output voltage of the APF should be controlled. For this to happen, at first a reference voltage is generated which when injected by APF will serve the desired purpose. Then the actual output voltage of the series connected APF is controlled using a PI controller such that the actual output voltage generated is equal to the reference value. The compensation strategy to compensate the harmonics is designed based on "Dual Instantaneous Reactive Power Theory". In general, the power company tries to generate electric power at sinusoidal and balanced voltage. To achieve this condition, the load current at the Point of Common Coupling (PCC) should be co-linear with the supply voltage. This condition is satisfied if the load is a linear, balanced and resistive. This condition is expressed in equation form as-

$$
v=R_{e} i
$$

where $R_{e}$ is the equivalent resistance Thus, the average power supplied by the source is given as-

$$
P=R_{e} I^{2}
$$

In case of unbalanced loads, where harmonics exist, only the fundamental component of the current helps in supplying the active power to the load. So the current in the Equation (3.15) is only the fundamental component and is represented as I1.

The load power is the summation of the source power and the compensator power. But the power exchange by the compensator should be null. So the load power is equal to the source power. 


\subsection{Reference Vector Generation}

To control the series connected APF the reference vector should be generated and compared with the actual voltage vector [1]. The reference voltage vector given by Equation (21) is generated by the following control block. The fundamental component calculation needs the grid voltage angle to calculate the value. The grid voltage angle necessary for this calculation is extracted by using a Phased Lock Loop (PLL) (Figure 6).

A Low pass filter (LPF) is used in the fundamental calculation block to filter out the harmonics and extract the fundamental component. A comparison is made between the actual and reference values of the output voltage of TCLC-HAPF. The error is passed through a PID controller. The gain values of the controller are tuned in such a way that the error is zero and the actual value matches almost with the reference value. If this condition is achieved perfectly then the TCLC-HAPF improves the quality of power generated to the load by filtering out the harmonics and thus improving the performance of the system.

\subsection{Presentation of $\mathrm{H}-\infty$ Command}

The $\mathrm{H}-\infty$ command (still called advanced frequent control or multivariable robust command) is a new approach to the Frequency Automatic; it was initiated by Zames in the early 1980s and developed, in particular by Doyle, Glover, Khargonekar and Francis; it has in recent years become one of the flagship methods of "robust control" [23]; it is used for the rapid development of robust

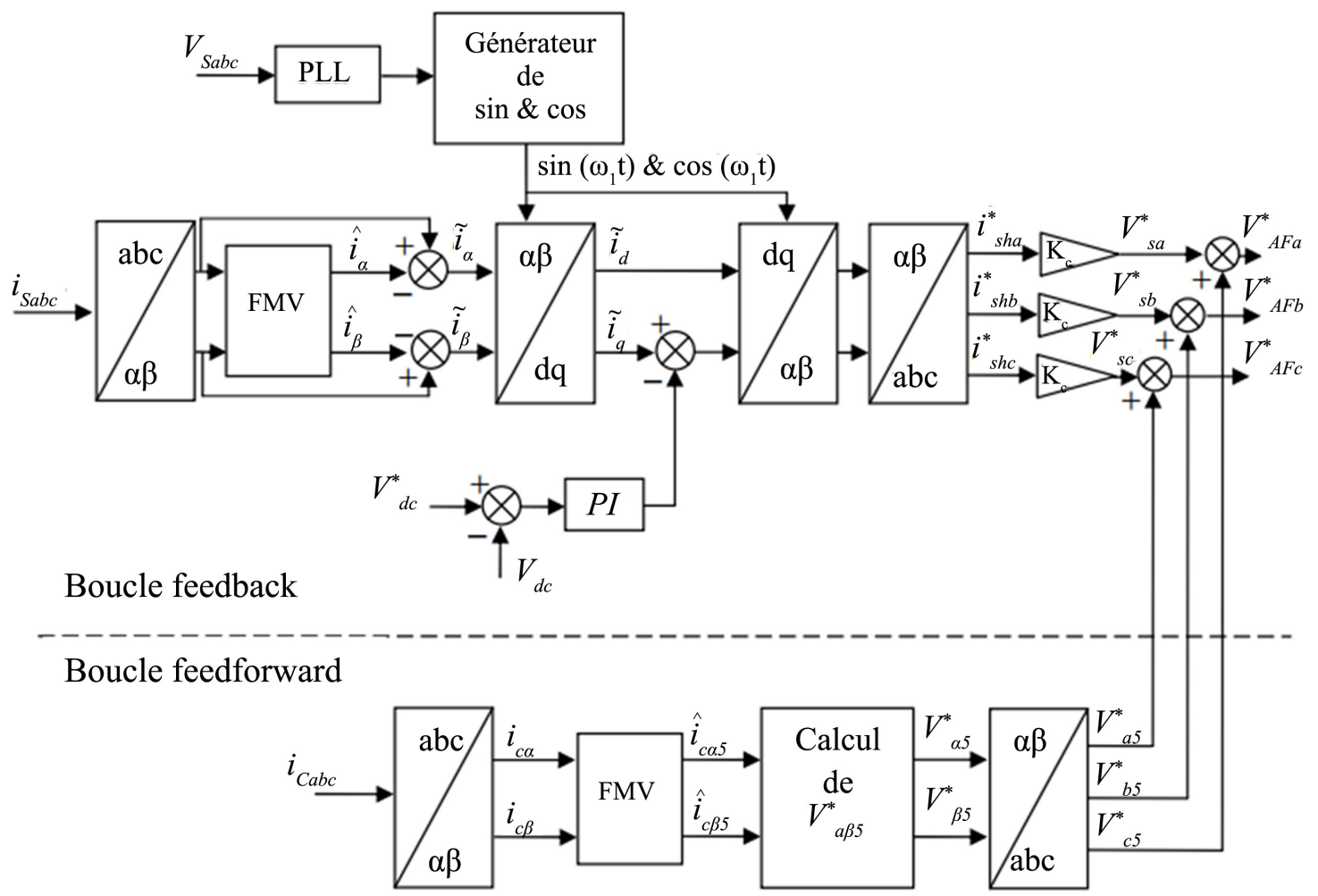

Figure 6. Classic control diagram of the adaptive hybrid filter. 
control laws of stationary and multivariable linear systems [1] [24] the principle of the $\mathrm{H}-\infty$ Command provides a solution (if it exists) to the control problem with a number of constraints [15]. It takes into account the specifications which can be classified into four classes of specifications: [15] [25]

- Reference trajectory tracking (guidelines): this is to study the influence of the reference signal $r(t)$ on the error signal $E(t)$

- Rejection/mitigation of disturbance signals: this is the to study the influence of the $b(t)$ disturbance signal on the Error Signal $E(t)$

- Measurement Noise Mitigation: it was intended to study the influence of noise signals $w(t)$ on the signal $U(t)$ and on the output signal $y(t)$

- Moderate control: it is a question of studying the influence of the reference signals $r(t)$ and the disturbance signal $b(t)$ on the command signal $u(t)$

\subsection{Standard Problem of $H-\infty$}

The $\mathrm{H}-\infty$ synthesis uses the concept of standard problem, which is shown in Figure 7: the $\mathrm{P}(\mathrm{s})$ transfer matrix models the dynamic interactions between 2 sets of inputs and 2 sets of outputs: vector IV represents external inputs, such as reference signals, disturbances, noises; The vector II represents the commands; the e signals are chosen to characterize the right functioning of "system"; Finally, y represents the measures available to develop the order.

\section{Riccati Equation Solution}

From the following model below;

$$
\left\{\begin{array}{l}
x_{(t)}=A x_{(t)}+B_{w} w_{(t)}+B_{u} u_{(t)} \\
Z_{(t)}=C_{z} x_{(t)}+D_{z w} w_{(t)}+D_{z u} u_{(t)} \\
y_{(t)}=C_{y} x_{(t)}+D_{y w} w_{(t)}+D_{y u} u_{(t)}
\end{array}\right.
$$

with $x(t)$ : is the state vector

$u(t)$ : is the vector input or command

$y(t)$ : is the observation vector or exit.

$A=$ evolution or state matrix

$B_{u}=$ control or input matrix

$C_{y}=$ observation matrix

$D_{z u}=$ coupling inputs outputs matrix (direct transmition)

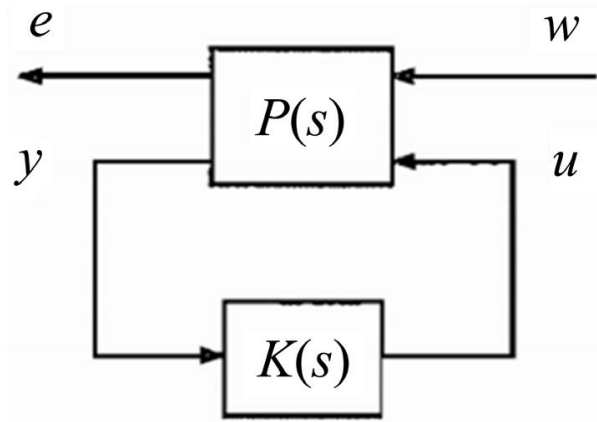

Figure 7. The $\mathrm{H}-\infty$ synthesis concept of standard problem. 
For the problem $\mathrm{H}-\infty$ standard certain assumption must be respected:

H1) -the even $\left(A B_{U}\right)$ is stabilized or commendable

-The pair $\left(C_{Y}, A\right)$ is detectable or observable

These two conditions guarantee the existence of the corrector that stabilizes the closed loop system.

H2) $\operatorname{rank}\left(D_{Z U}\right)=M_{U}$ and $\operatorname{rank}\left(D_{Y W}\right)=P_{Y}$ these are the conditions to ensure that the $K_{(P)}$ corrector is clean. That is there are many $Z$ controlled outputs as $U\left(P_{Z} \geq M_{U}\right)$ and that there are at least many $\mathrm{W}$-screen entries as there are $Y\left(M_{W}>P_{Y}\right)$.

H3) rank $\left[\begin{array}{cc}A-j w I_{n} & B_{u} \\ C_{z} & D_{z u}\end{array}\right]=n+m_{u}$ guarantees that the transfer $P_{Z U}$ has no zero on the imaginary axis.

H4) rank $\left[\begin{array}{cc}A-j w I_{n} & B_{w} \\ C_{y} & D_{y w}\end{array}\right]=n+P_{y}$ guarantee that the transfer $P_{Y W}$ has no zero on the imaginary axis.

These four hypotheses must be verified. Using Matlab

To obtain the simplest expressions, the following additional conditions are introduced.

$$
D_{z w}=0 ; \quad D_{z u}^{\mathrm{T}}\left[\begin{array}{ll}
C_{z} & D_{z u}
\end{array}\right]=\left[\begin{array}{cc}
0 & I_{m u}
\end{array}\right] ; \quad D_{y u}=0 ;\left[\begin{array}{c}
B_{w} \\
D_{y w}
\end{array}\right] D_{y w}^{\mathrm{T}}=\left[\begin{array}{c}
0 \\
I_{p y}
\end{array}\right]
$$

So there is a $K(p)$ corrector solution to the problem H冈standard

1) The Hamiltonian Matrix

$\left[\begin{array}{cc}A & \gamma^{-2} B_{w} B_{w}^{\mathrm{T}}-B_{u} B_{u}^{\mathrm{T}} \\ -C_{z}^{\mathrm{T}} C_{z} & -A^{\mathrm{T}}\end{array}\right]$ has no values of its own on the imaginary axis and there is a sysmmetrical matrix $X_{\infty} \geq 0$ such as:

$$
X_{\infty} A+A^{\mathrm{T}} X_{\infty}+X_{\infty}\left(\gamma^{-2} B_{w} B_{w}^{\mathrm{T}}-B_{u} B_{u}^{\mathrm{T}}\right) X_{\infty}+C_{z}^{\mathrm{T}} C_{z}=0
$$

\section{2) The Hamiltonian Matrix}

$\left[\begin{array}{cc}A^{\mathrm{T}} & \gamma^{-2} C_{z}^{\mathrm{T}} C_{z}-C_{y}^{\mathrm{T}} C_{y} \\ -B_{w} B_{w}^{\mathrm{T}} & A\end{array}\right]$ has no values of its own on the axis imaginary and there is a symmetrical matrix $Y_{\infty} \geq 0$ such as

$$
Y_{\infty} A+A^{\mathrm{T}} Y_{\infty}+Y_{\infty}\left(\gamma^{-2} C_{z}^{\mathrm{T}} C_{z}-C_{y}^{\mathrm{T}} C_{y}\right) Y_{\infty}+B_{w} B_{w}^{\mathrm{T}}=0
$$

3) $-\rho\left(X_{\infty} Y_{\infty}\right)<\gamma^{2}$ or $\rho$ corresponds to the module of the highest value (spectral radius). In addition, all $K(P)$ correctors responding to the problem are given by $K(P)=F_{l}\left[K_{a}(P), \varnothing(P)\right]$ or $\varnothing(P)$ is a stable function, standard $H_{\infty}$ is below the $Y$ and $K_{a}(P)$

$$
K_{a}(P)=\left[\begin{array}{ccc}
\widehat{A_{\infty}} & -Z_{\infty} L_{\infty} & Z_{\infty} B_{u} \\
F_{\infty} & 0 & I_{m u} \\
-C_{y} & I_{p y} & 0
\end{array}\right]
$$

with

$$
\widehat{A_{\infty}}=A+\gamma^{-2} B_{w} B_{w}^{\mathrm{T}} X_{\infty}+B_{u} F_{\infty}+Z_{\infty} L_{\infty} C_{y}
$$




$$
\begin{aligned}
& F_{\infty}=-B_{u}^{\mathrm{T}} X_{\infty} \\
& L_{\infty}=-Y_{\infty} C_{y}^{\mathrm{T}} \\
& Z_{\infty}=\left(I_{n}-Y^{-2} X_{\infty} Y_{\infty}\right)^{-1}
\end{aligned}
$$

A particular corrector can be obtained as the central corrector, obtained by taking 0 , which gives:

$$
K_{0}(P)=\left[\begin{array}{cc}
\widehat{A_{\infty}} & -Z_{\infty} L_{\infty} \\
F_{\infty} & 0
\end{array}\right]
$$

\section{4) Equivalent model of the HAPF (applying $\mathrm{H}-\infty$ to filter) (Figure 8)}

The equivalent reactance gives us:

$$
X_{\text {TCLCxf }}=\frac{\pi X_{l P F f} X_{c P F f}}{X_{c P F f}\left(2 \pi-2 \alpha_{x}+\sin 2 \alpha_{x}\right)-\pi X_{l P F f}}+X_{l P F f}
$$

Avec $X_{l c f}=w l_{c} ; X_{l P F f}=w l_{P F} ; X_{c f P F}=1 / w C_{P F} ; w=2 \pi f$

From the equivalent model we have the mesh equation;

$$
\begin{gathered}
V_{x}+X_{T c L c x f} I_{c x n}-V_{a f}=0 \\
\text { suppose } \beta=\frac{\pi X_{l P F f} X_{c P F f}}{X_{c P F f}\left(2 \pi-2 \alpha_{x}+\sin 2 \alpha_{x}\right)-\pi X_{l P F f}}
\end{gathered}
$$

where $V_{x}+\beta I_{c x n}+X_{l c f} I_{c x n}-V_{a f}=0$ by posing $U_{l c f}=X_{l c f} I_{c x n}$ this implies $U_{l c f}=-\beta I_{c x n}+V_{a f}-V_{x}$ and $L_{c} \frac{\mathrm{d} I_{c n x}}{\mathrm{~d} t}=-\beta I_{c x n}+V_{a f}-V_{x}$ which ultimately gives

$$
\frac{\mathrm{d} I_{c n x}}{\mathrm{~d} t}=\frac{-\beta}{L_{c}} I_{c x n}+\frac{V_{a f}}{L_{c}}-\frac{V_{x}}{L_{c}}
$$

However, the current at the entrance to the active Filter gives:

$$
\begin{gathered}
I_{a f}=I_{F a}-I_{F b} \quad \text { which is equivalent to } \frac{\mathrm{d} Q_{a f}}{\mathrm{~d} t}=I_{F a}-I_{F b} \\
\frac{C_{d c} \mathrm{~d} V_{a f}}{\mathrm{~d} t}=I_{F a}-I_{F b} \text { which is still equivalent to: }
\end{gathered}
$$

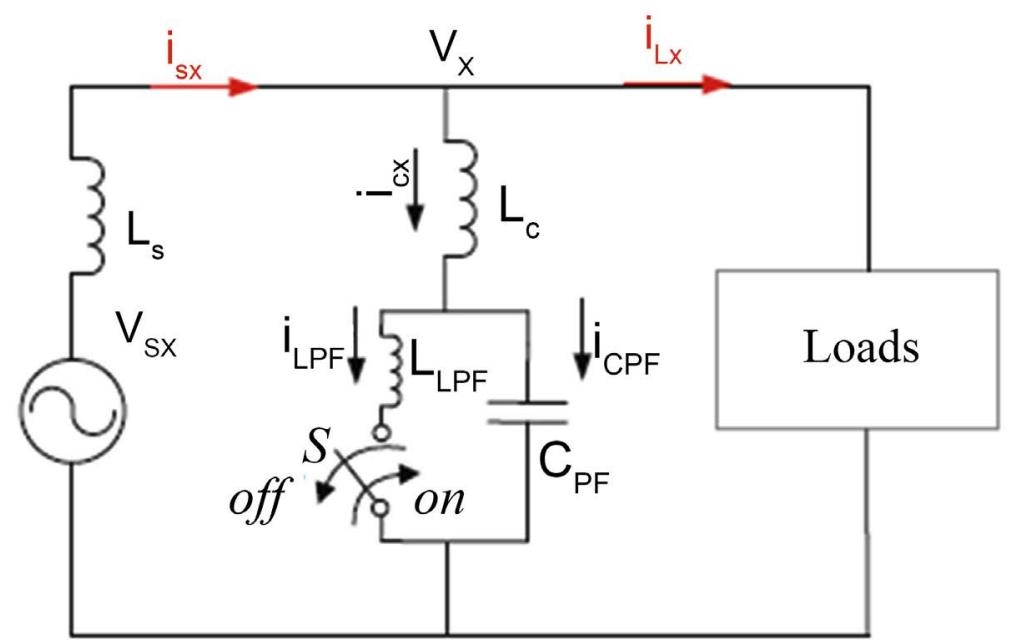

Figure 8. Equivalent model of the HAPF (applying $\mathrm{H}-\infty$ to filter). 


$$
\frac{\mathrm{d} V_{a f}}{\mathrm{~d} t}=\frac{1}{C_{d c}}\left(I_{F a}-I_{F b}\right)
$$

So we obtain these two equations

$$
\begin{gathered}
\frac{\mathrm{d} I_{c n x}}{\mathrm{~d} t}=\frac{-\beta}{L_{c}} I_{c x n}+\frac{V_{a f}}{L_{c}}-\frac{V_{x}}{L_{c}} \\
\frac{\mathrm{d} V_{a f}}{\mathrm{~d} t}=\frac{1}{C_{d c}}\left(I_{F a}-I_{F b}\right)
\end{gathered}
$$

Lets translate these two equations into Parks landmark

$$
\begin{aligned}
\frac{\mathrm{d} I_{d}}{\mathrm{~d} t} & =\frac{-\beta}{L_{c}} I_{d}+w I_{q}-\frac{V_{x d}}{L_{c}} \\
\frac{\mathrm{d} I_{q}}{\mathrm{~d} t} & =\frac{-\beta}{L_{c}} I_{q}-w I_{d}-\frac{V_{x q}}{L_{c}} \\
\frac{\mathrm{d} V_{a f d}}{\mathrm{~d} t} & =\frac{1}{C_{d c}}\left(I_{d}-I_{l d}\right)+w V_{a f q} \\
\frac{\mathrm{d} V_{a f d}}{\mathrm{~d} t} & =\frac{1}{C_{d c}}\left(I_{q}-I_{l q}\right)-w V_{a f d}
\end{aligned}
$$

with

$-I_{d}$ et $I_{q}$ : represents variations in park components associated with line currents at the entrance to the LCL filter

$V_{a f d}$ et $V_{a f q}$ : presents variations in Park components associated with voltage in the LCL filter capacitive bus.

$-I_{l d}$ et $I_{l q}$ : presents variations in Park components associated with currents at the right straightener entrance.

The appearing command vector $U$, which includes the non-linearities of the system, is written as follows:

$$
U=\left(I_{l d}, I_{l q}\right)^{t}
$$

The state vector $X$

$$
X=\left(I_{d}, I_{q}, V_{a f d}, V_{a f q}\right)^{t}
$$

Finally we deduct our state matrix, entry and exit

- Matrice d'état $A$

$$
A=\left(\begin{array}{cccc}
\frac{-\beta}{L_{c}} & w & \frac{-1}{L_{c}} & 0 \\
-w & \frac{-\beta}{L_{c}} & 0 & \frac{-1}{L_{c}} \\
\frac{-1}{C_{d c}} & 0 & 0 & w \\
0 & \frac{1}{L_{c}} & -w & 0
\end{array}\right)
$$

\section{- Matrice d'entrée $B$}




$$
B=\left(\begin{array}{cc}
0 & 0 \\
0 & 0 \\
\frac{-1}{L_{c}} & 0 \\
0 & \frac{-1}{L_{c}}
\end{array}\right)
$$

\section{- Matrice de sortie $C$}

$$
C=\left(\begin{array}{llll}
0 & 0 & 1 & 0 \\
0 & 0 & 0 & 1
\end{array}\right)
$$

with the matrice obtain above will permit us to have a good functioning of the $\mathrm{H} \infty$ corrector.

\section{Simulation Results and Discussions}

The proposed control strategy is simulated in MATLAB SIMULINK environment to check the performance of the control strategy in improving the system behavior. The simulation is carried under two different conditions:

Unbalance Non-linear Load

Balance Non-linear Load

The performance of the system with the proposed control strategy under different conditions is discussed in detail in the following section.

\section{Simulation Results with Non-Linear Load (Table 2)}

To study the performance of the system when the source voltage is in equilibrium and connected to a non-linear load with $R_{I}$ and $L_{c}$. The load turns to inject harmonic back to the source current coursing other linear load to suffer malfunction. The simulink model of the system is shown in Figure 9.

As observed from the above current curve of a single phased compared with that of Figure 10, it's clearly seen that due to the injected harmonics to the system has changed the sharp of the curve, therefore by applying our filter topology to smoothing the sharp of the curve (Figure 11).

\section{Unbalanced Non-Linear Load (Table 3)}

The simulink model is same as that of the balance load while maintaining similar

Table 2. System parameters nonlinear load.

\begin{tabular}{cccc}
\hline System parameters & value & & \\
\hline Supply voltage & $380 \mathrm{v}$ & $I_{c}$ & $5 \mathrm{mH}$ \\
Load resistance & $30 \Omega$ & $I_{P F}$ & $30 \mathrm{mH}$ \\
Load inductance & $1 \mathrm{mH}$ & $C_{P F}$ & $160 \mathrm{uF}$ \\
& & $C_{d}$ & $1500 \mathrm{uF}$ \\
& & $\beta$ & $-3,624,192$ \\
\hline
\end{tabular}



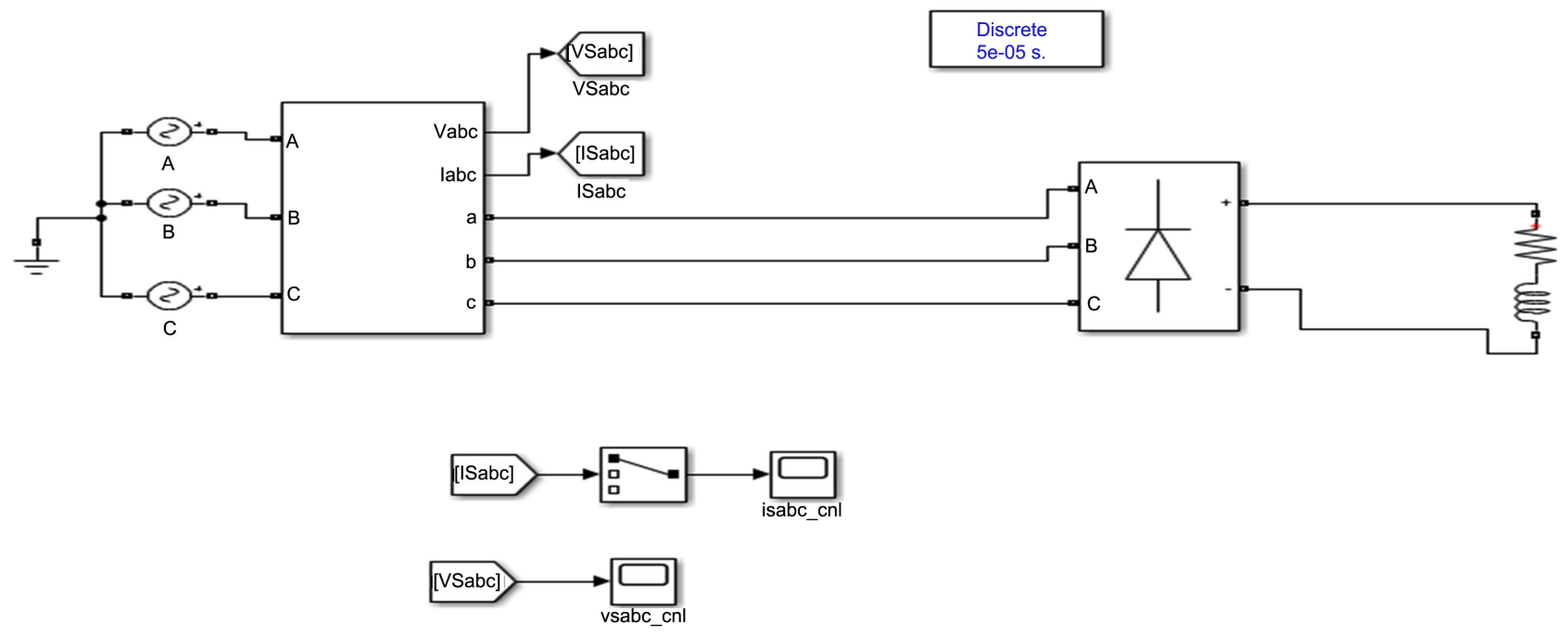

Figure 9. Model simulink for balanced linear load.
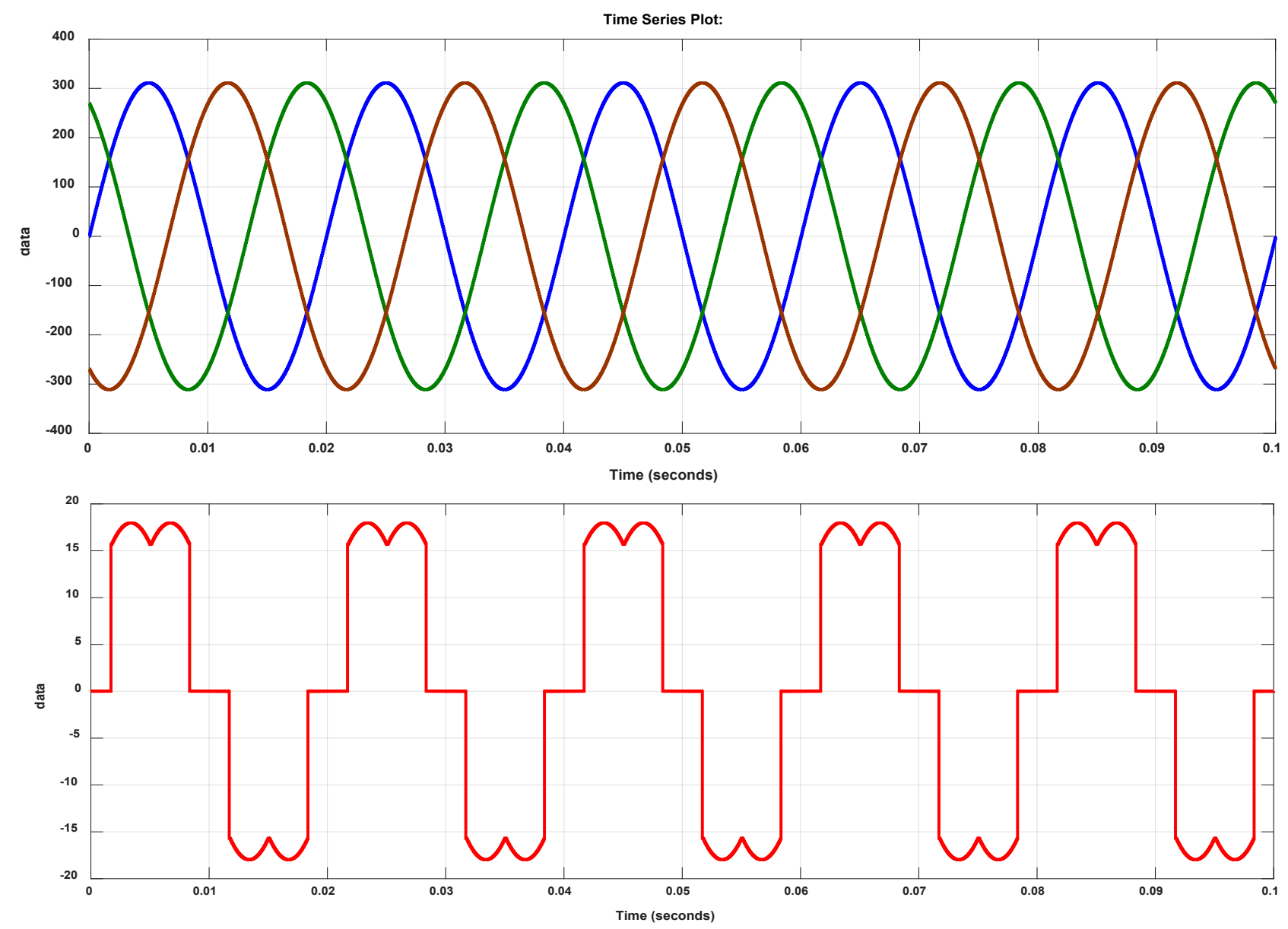

Figure 10. Source current with harmonics.

parameters, with an additional unbalanced load. See simulink model in Figure 12.

To study the performance of the system when the load is unbalance with the 


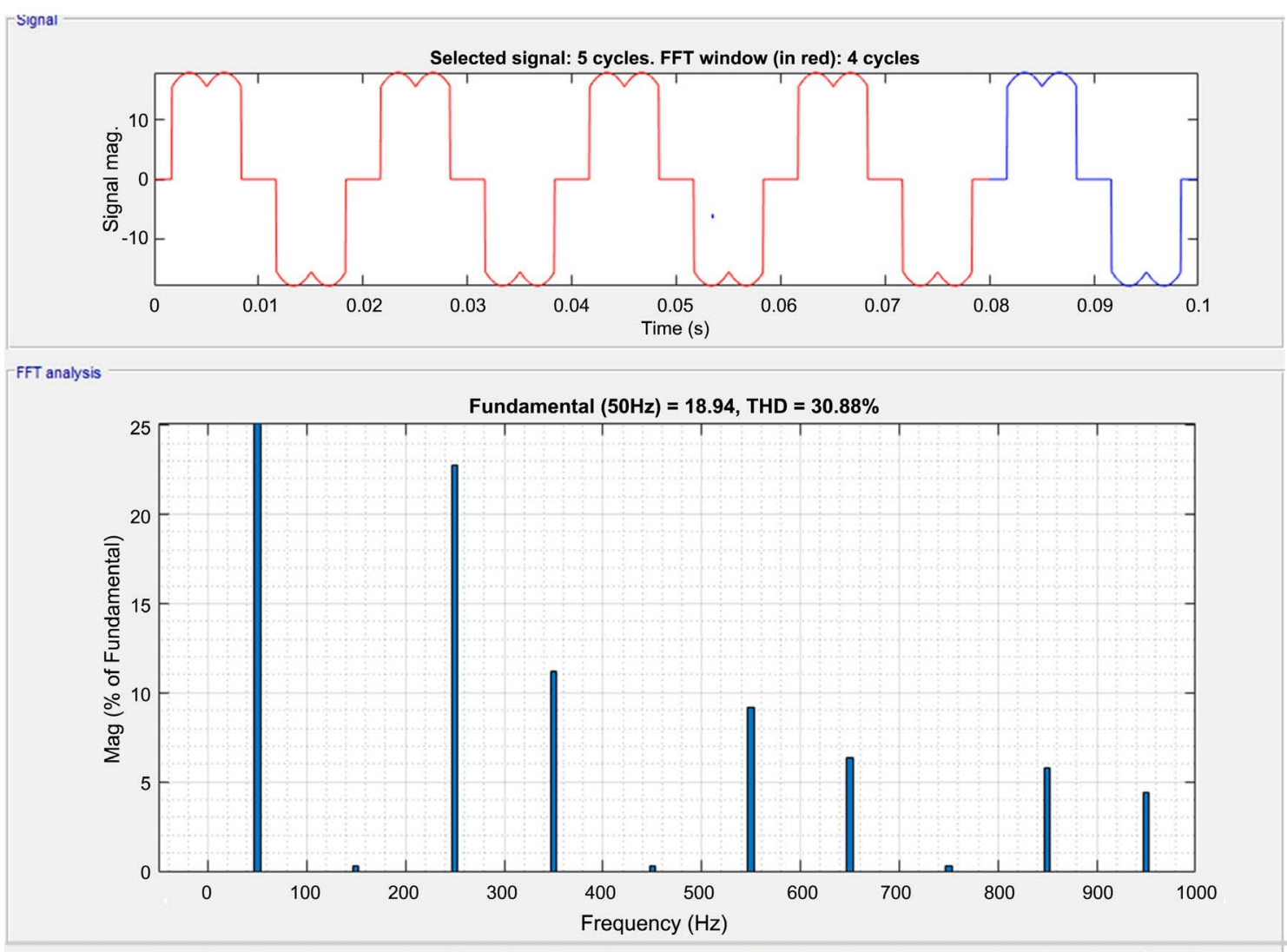

Figure 11. THD of the balanced nonlinear load.

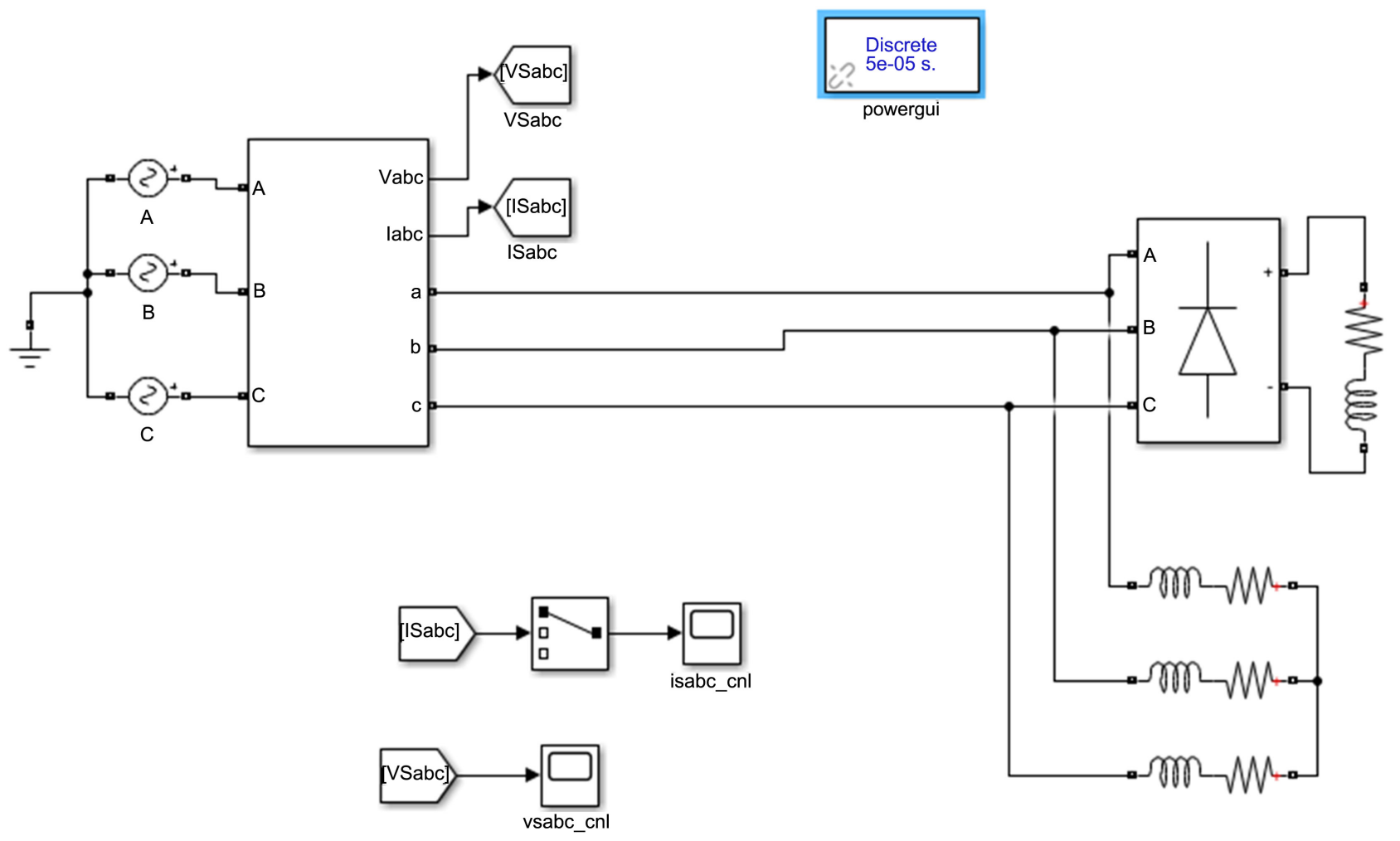

Figure 12. Simulink model of an unbalanced load. 
Table 3. System parameter of unbalanced nonlinear load.

\begin{tabular}{ccc}
\hline System parameters & value \\
Supply voltage & Balanced load & $380 \mathrm{v}$ \\
Load resistance & & \\
Load inductance & Unbalanced load & $1 \mathrm{mH}$ \\
& & \\
Load resistance R1 & & $26 \Omega$ \\
R2 & $15 \Omega$ \\
R3 & $30 \Omega$ \\
L1 & $90 \mathrm{mH}$ \\
L2 & $100 \mathrm{mH}$ \\
L3 & $85 \mathrm{mH}$ \\
\hline
\end{tabular}

above parameters, the simulation is carried out. And the simulation result of phase1 is presented in Figure 12, showing the difference in amplitude.

From the above analysis it is obvious that each line with respect of the unbalanced load injected to the system has caused different distortion in the lines (phase) making each line to observed different THD $23.98 \%, 22.34 \%, 30.48 \%$ as shown in Figure 13.

\subsection{Comparative Study of System before Filtering}

A comparative study is made to analyze the performance of the system at various operating conditions when operating with balanced load, unbalanced load and balanced voltage. The comparison is given in Table 4. From the results it is clear that the system behavior can be improved after the filter is connected and the source current THD will be very less and is within the IEEE permissible standards.

\subsection{Simulation Results of Non-Linear Load after Filtering}

The power system may experience unbalanced load and voltage source conditions at many times. Thus, the behavior of the proposed control strategy is analyzed

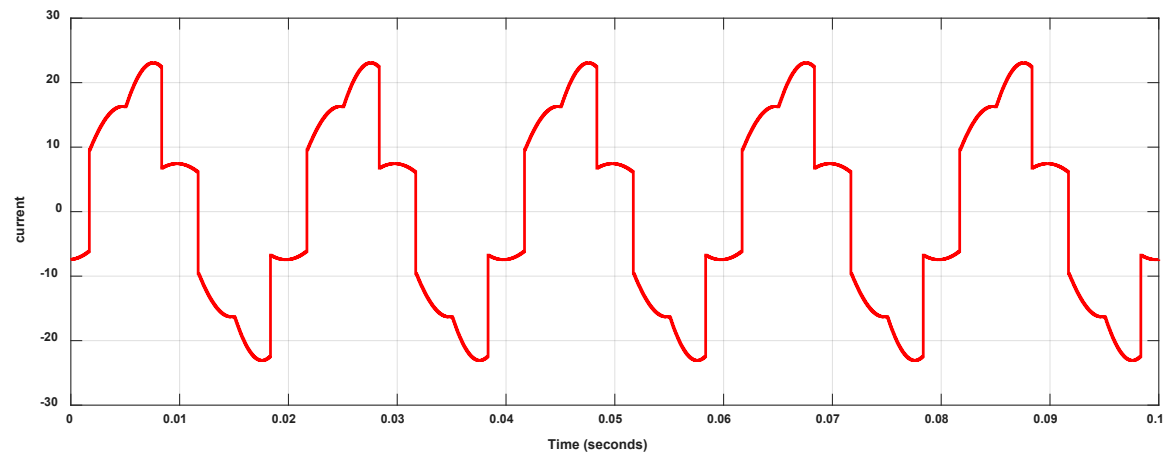




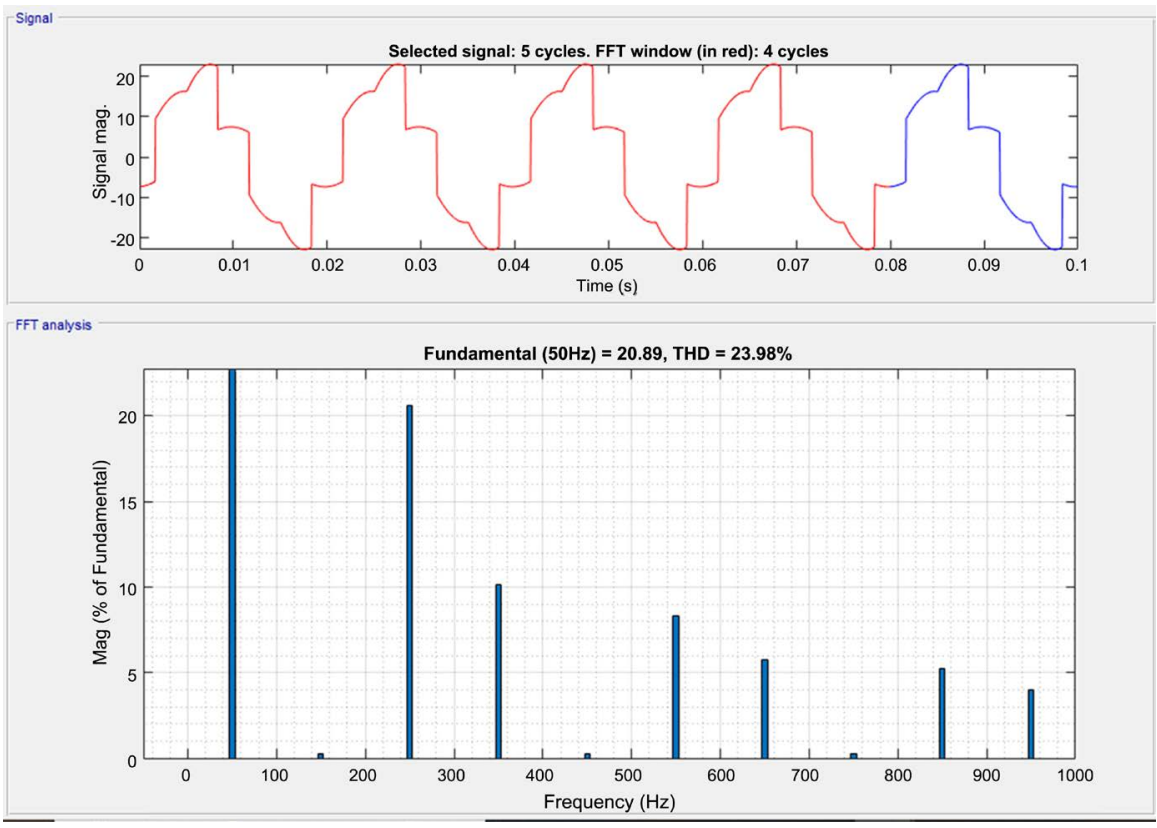

(a)
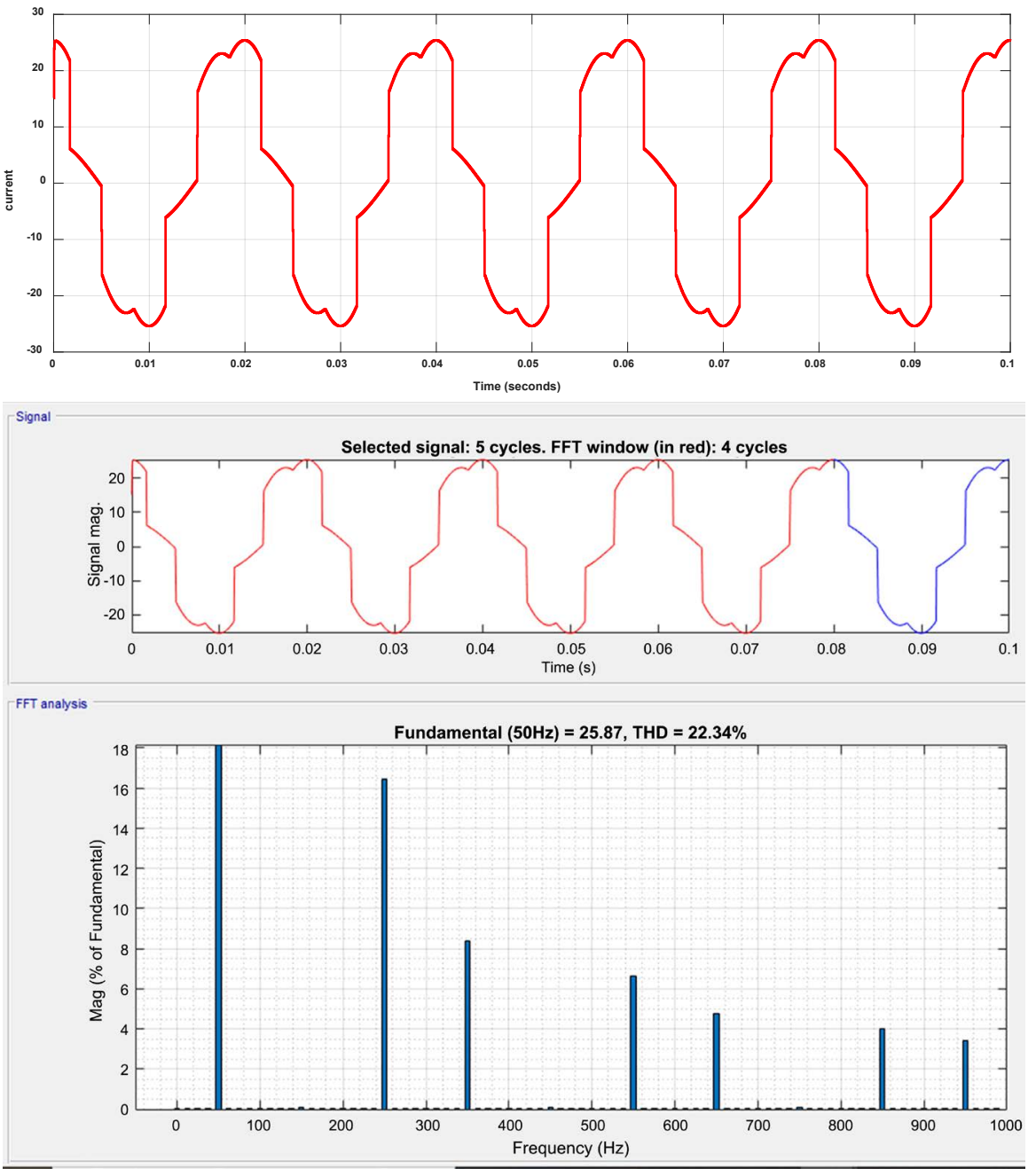

(b) 

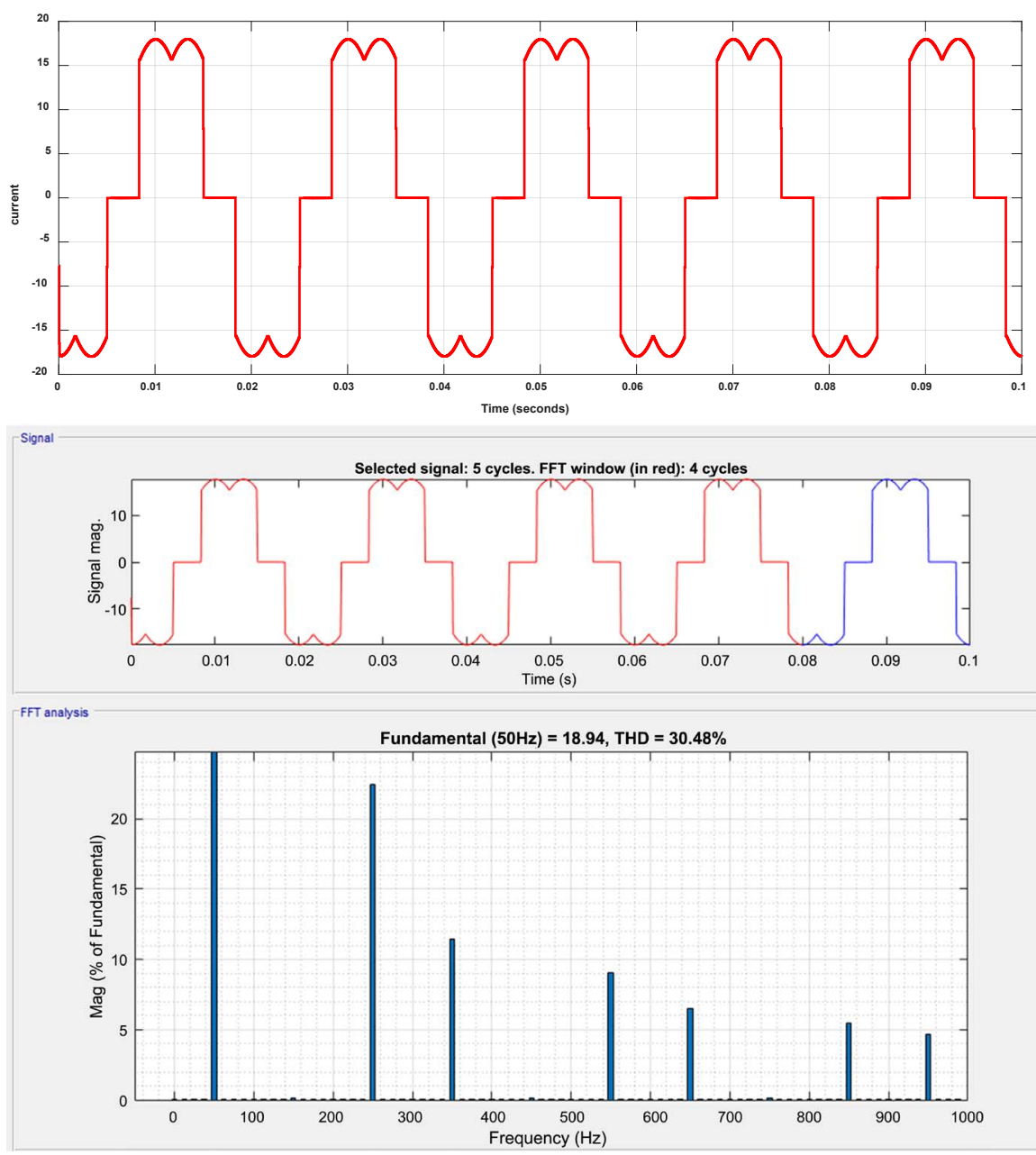

(c)

Figure 13. Source current curve and THD of phase before filtering. (a) Source current curve and THD of phase 1 before filtering; (b) Source current curve and THD of phase 2 before filtering; (c) Source current curve and THD of phase 3 before filtering.

Table 4. Comparison of source current THD.

\begin{tabular}{cc}
\hline Name & THD before filtering \\
\hline linear load & $00 \%$ \\
nonlinear load & $30 \%$ \\
Unbalanced nonlinear load phase 1 & $23.98 \%$ \\
Unbalanced nonlinear load phase 2 & $22.34 \%$ \\
Unbalanced nonlinear load phase 3 & $30.48 \%$ \\
\hline
\end{tabular}

by simulating it under non-linear load, unbalanced non-linear load and voltage condition. Here the non-linear load is created by connecting three single-phase uncontrolled rectifiers and resistor. The load voltage values are given in Table 5.

A passive filter is connected at PCC to eliminate fifth order harmonics. Also an active filter is also connected at the output of the VSI. The values of these filters along with load values are given in Table 5. The filter impedance should be less 
Table 5. System parameters.

\begin{tabular}{|c|c|}
\hline \multicolumn{2}{|c|}{ System parameters } \\
\hline Supply line & $380 \mathrm{v}$ \\
\hline Sours resistance (Rs) & $15 \mathrm{mH}$ \\
\hline frequency & $50 \mathrm{~Hz}$ \\
\hline \multicolumn{2}{|c|}{ load } \\
\hline Load resistance & $0.02 \Omega$ \\
\hline Load inductance & $15 \mathrm{mH}$ \\
\hline Non-linear resistance Rd & $30 \Omega$ \\
\hline \multicolumn{2}{|c|}{ filter } \\
\hline \multicolumn{2}{|c|}{ Passive filter } \\
\hline Lc & $12 \mathrm{mH}$ \\
\hline Lpf & $30 \mathrm{mH}$ \\
\hline Cpf & $31.1 \mu \mathrm{F}$ \\
\hline \multicolumn{2}{|c|}{ Active filter } \\
\hline Resistance & $2.1 \Omega$ \\
\hline Capacitor Cd & $1500 \mu \mathrm{F}$ \\
\hline $\mathrm{Vdc}$ & $105 \mathrm{v}$ \\
\hline
\end{tabular}

than the system impedance for effective filtering. The simulation is carried out under the following conditions; -balanced non-linear load-unbalanced non-linear load (phase 1, 2 and 3).

From observation and assumption the phase 3 of the unbalanced non-linear load will produced a level of THD with after filtering will respect the norms of THD. With the system parameters in Table 5, the proposed control strategy is simulated and the circuit diagram is shown in Figure 14. The MATLAB SIMULINK results are presented in Figures 15-17 respectively. Figure 18 shows the source current after compensation. The THD of this current is shown in Figure 16 which is (3.16\%) Now the THD of the current is less and the harmonic analysis is shown in Figure 17. The use of adaptive hybrid active power filter increases the performance of the system and the overall power factor is also improved. In addition, 5th order harmonics are greatly reduced.

Thus, from the above results it is clear that the harmonic filtering is effected when the source impedance is less than the filter impedance. Hence, to have better performance characteristics the source impedance should be always greater than the filter impedance.

The robust adaptive h-infinity control offers us a THD of 3.16\% after filtering a result admissible by the IEEE 519-1996 standard this result is consolidated by the work of [4]. The harmonic currents reach $8 \mathrm{~A}$. for the case of a balanced network. 


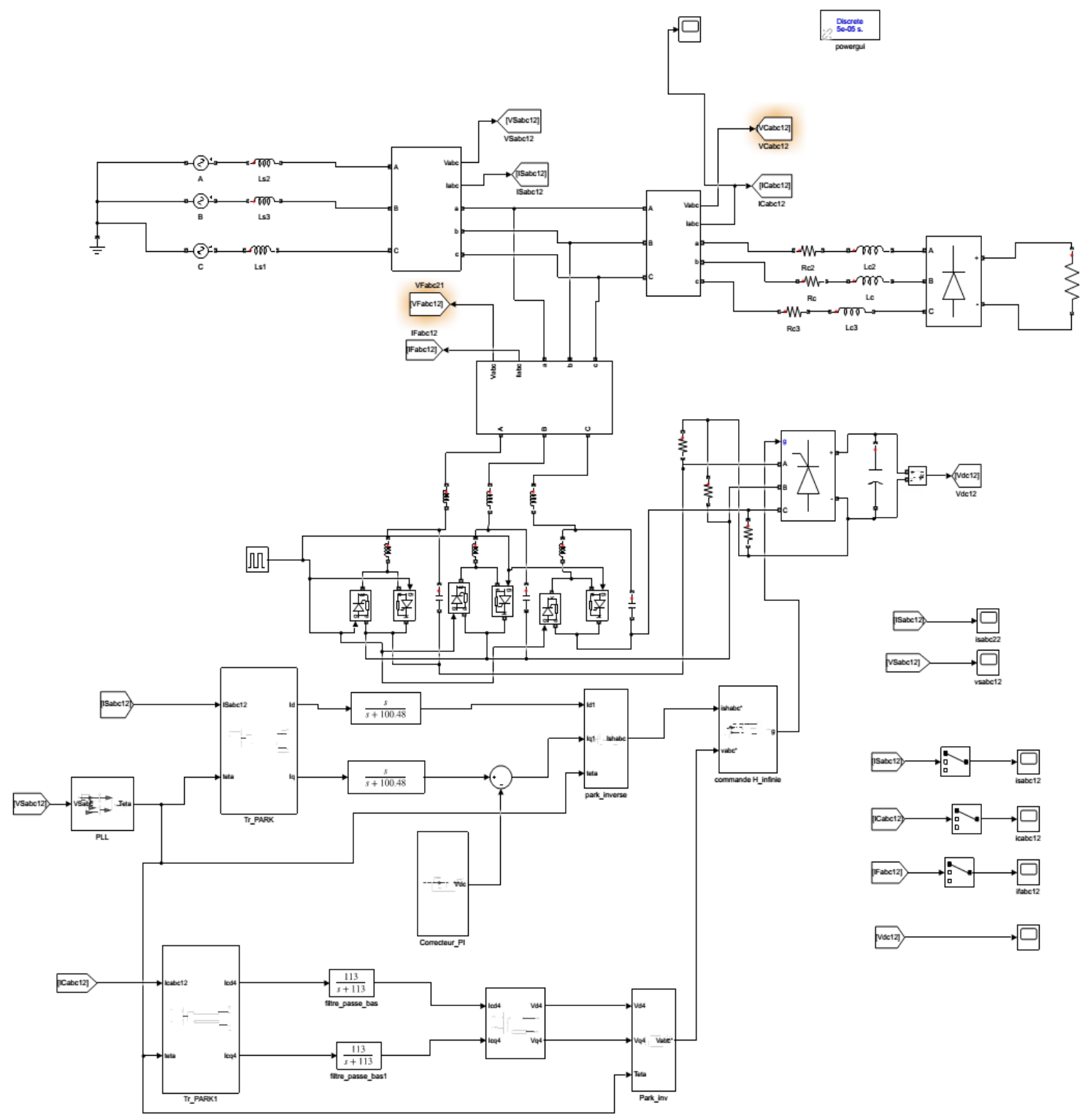

Figure 14. Simulink model with TCLC-HAPF.

Balanced non-linear load

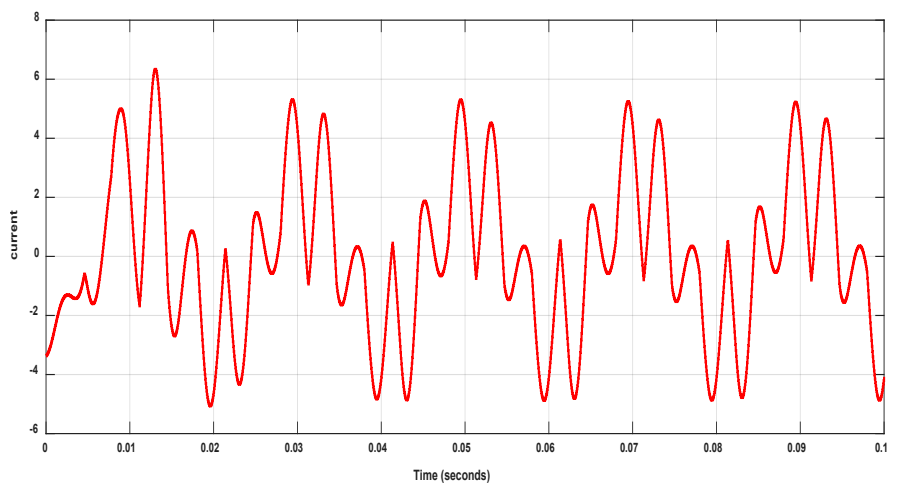

Harmonic Current injected by the Filter

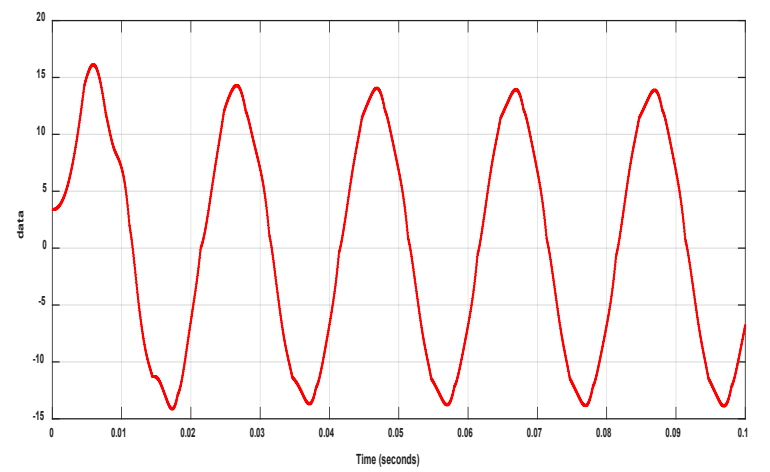

Source Current after Filtering

Figure 15. Harmonic and source current. 


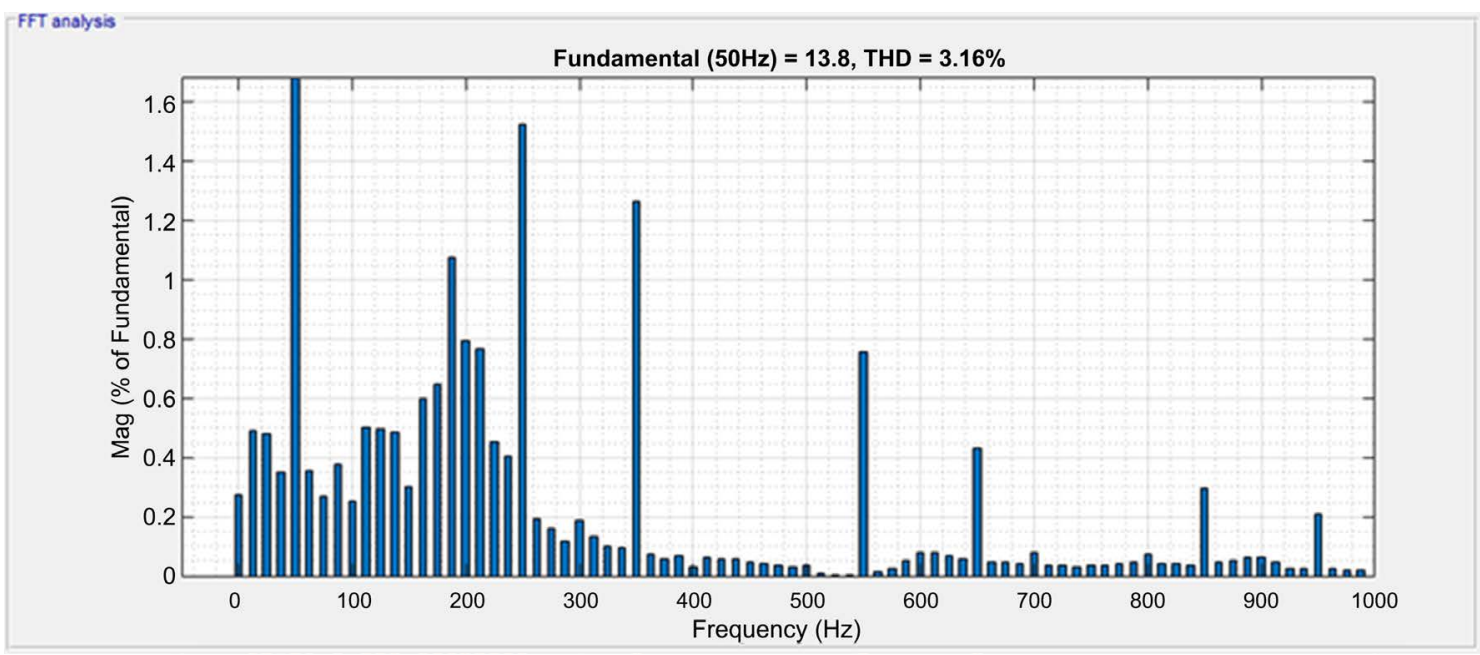

Figure 16. THD after filtering.

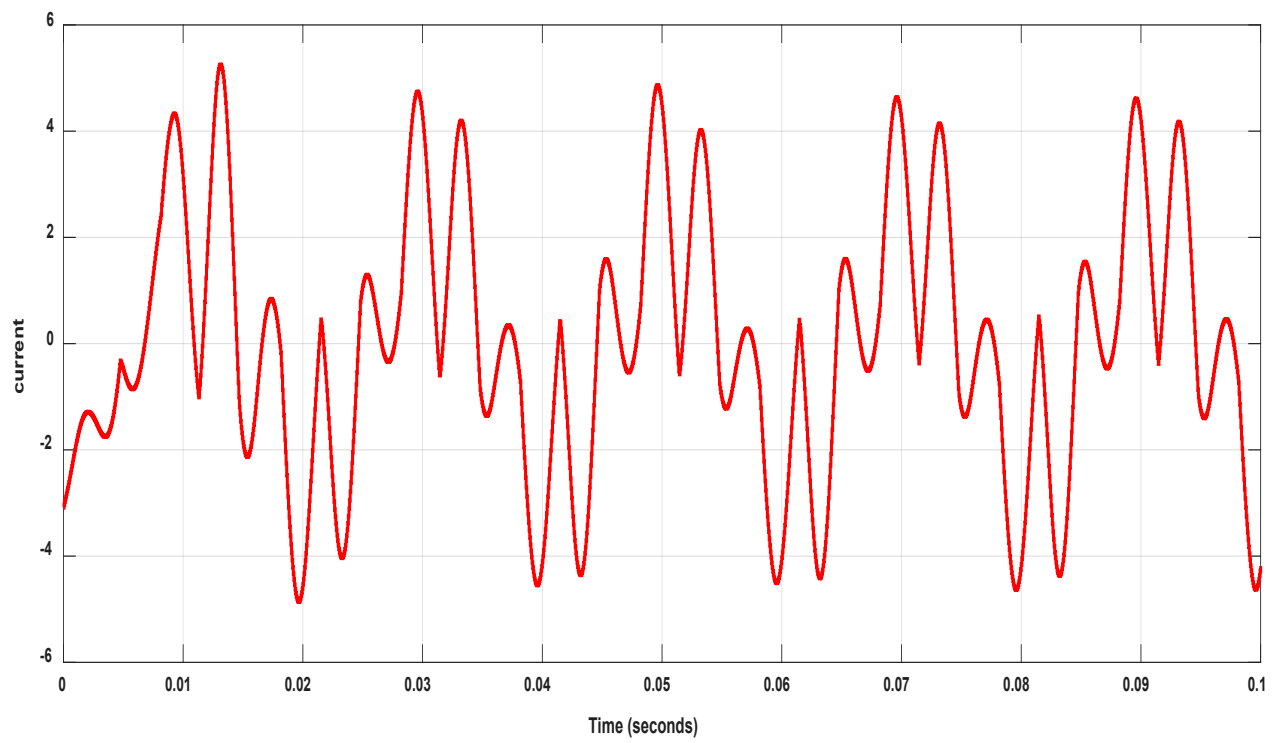

(a)

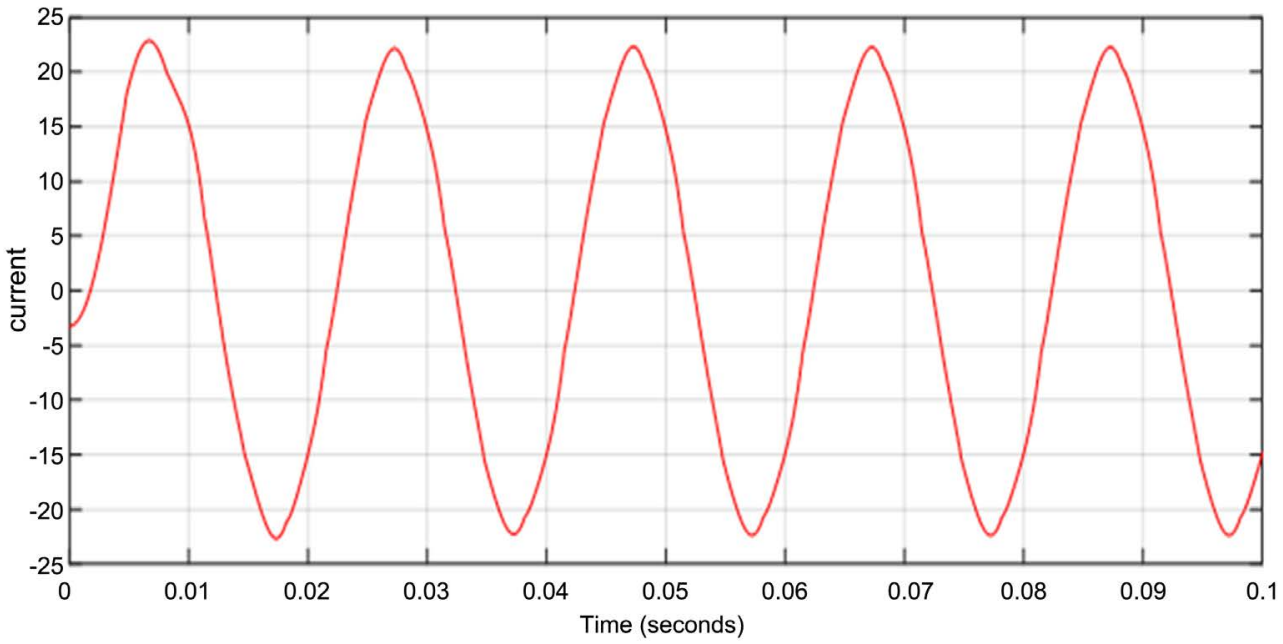

(b) 


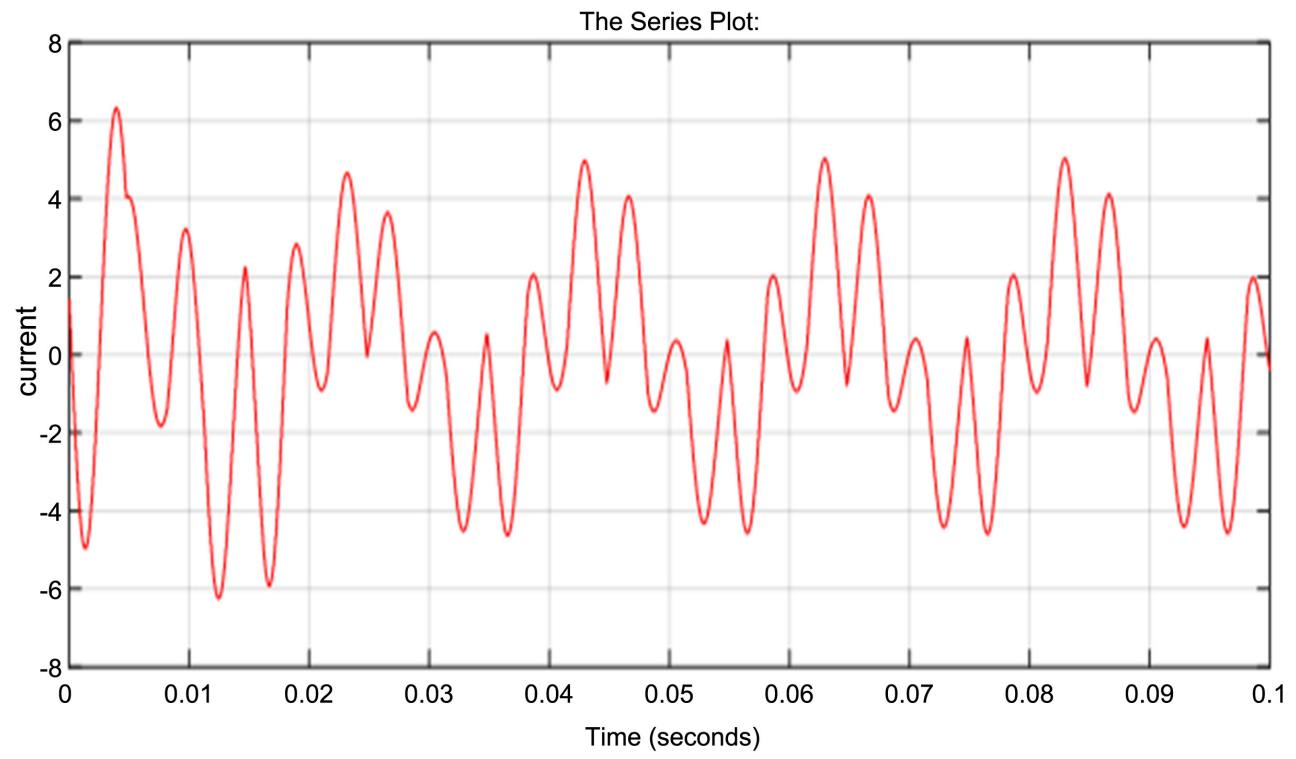

(c)

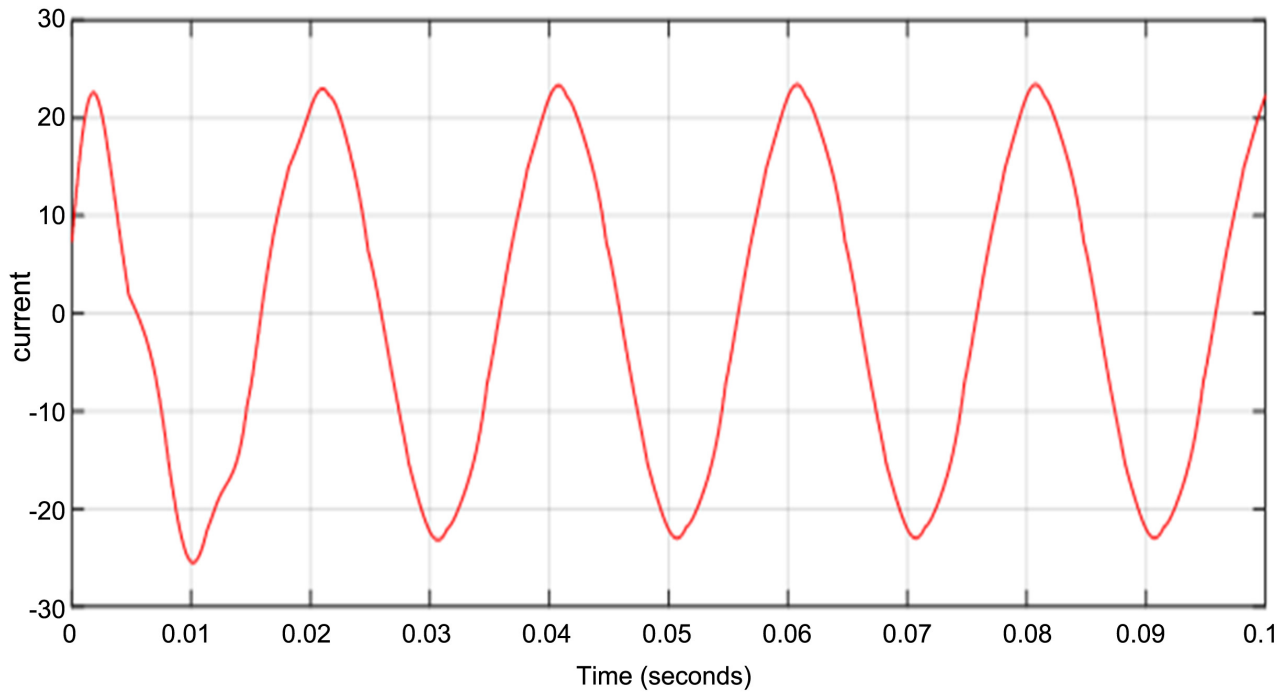

(d)

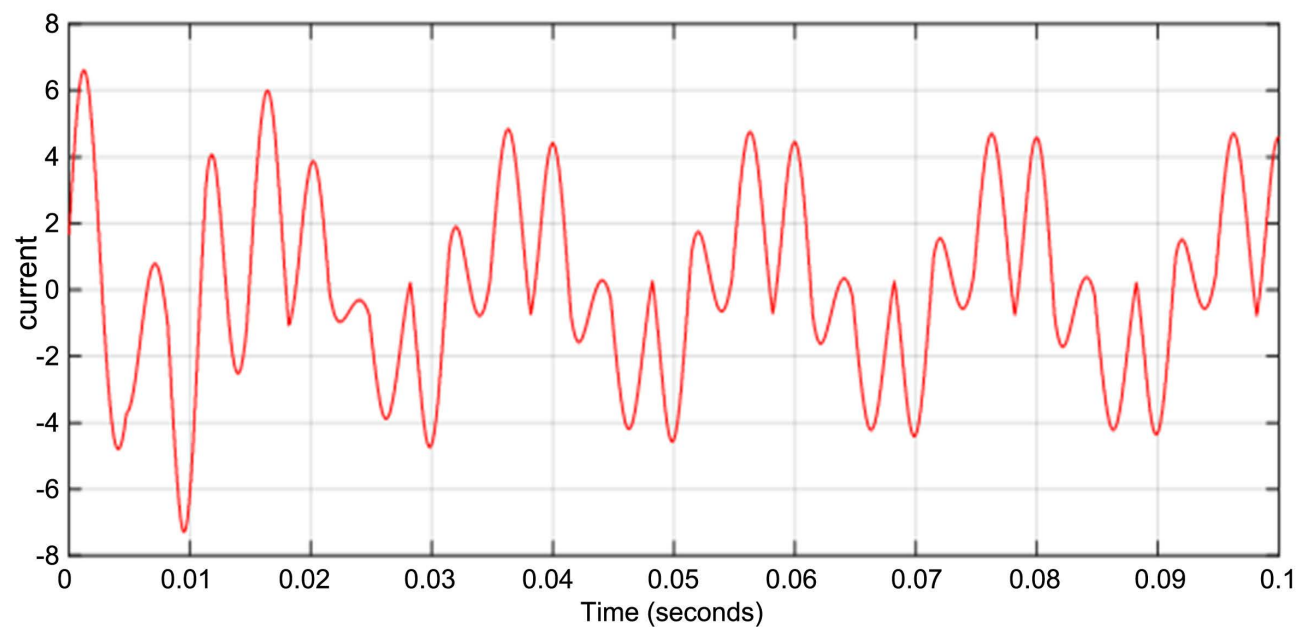

(e) 


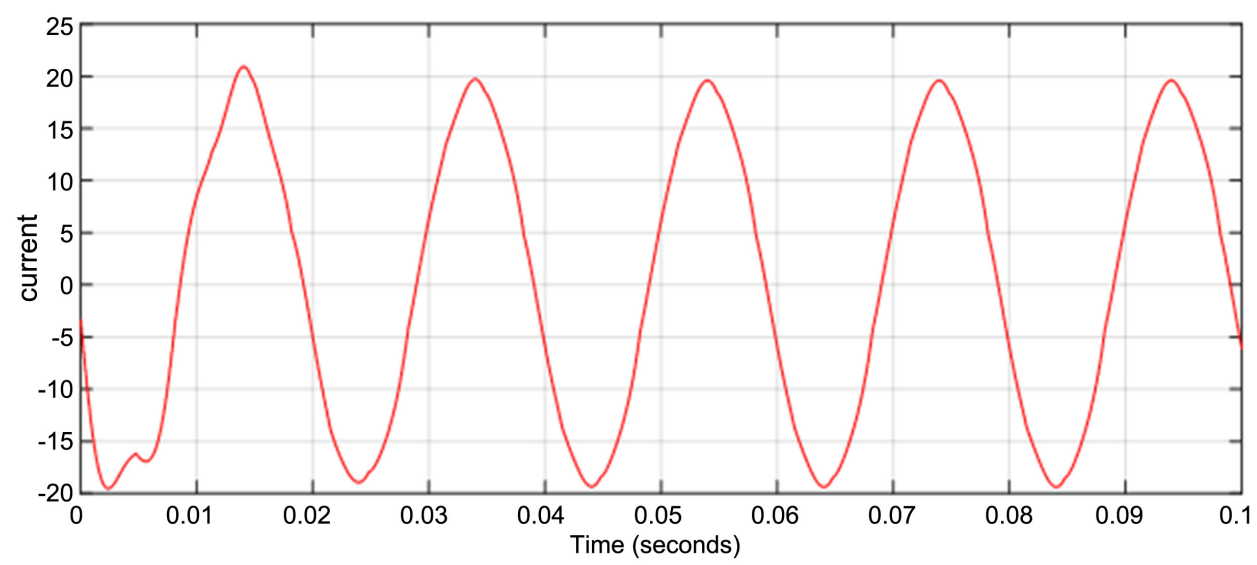

(f)

Figure 17. Harmonic current injected and source current. (a) Harmonic Current Injected by Filter on Phases 1; (b) Source Current on phases 1 after Filtering; (c) Harmonic Current Injected by Filter on Phases 2; (d) Source Current on phases 2 after Filtering; (e) Harmonic Current Injected by Filter on Phases 3; (f) Source Current on phases 3 after Filtering.

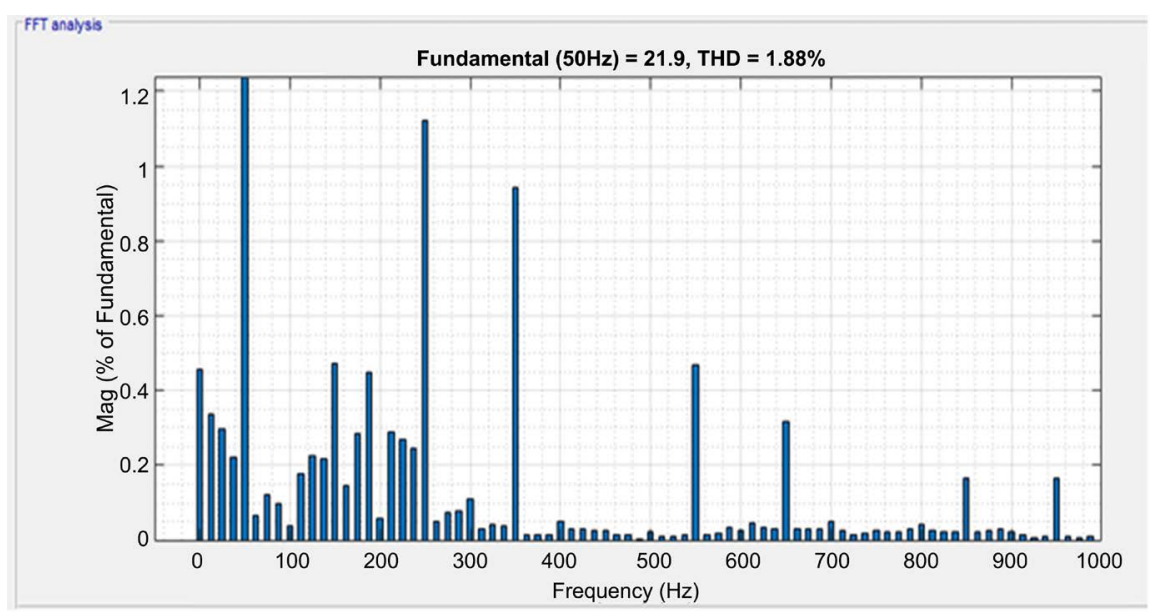

(a)

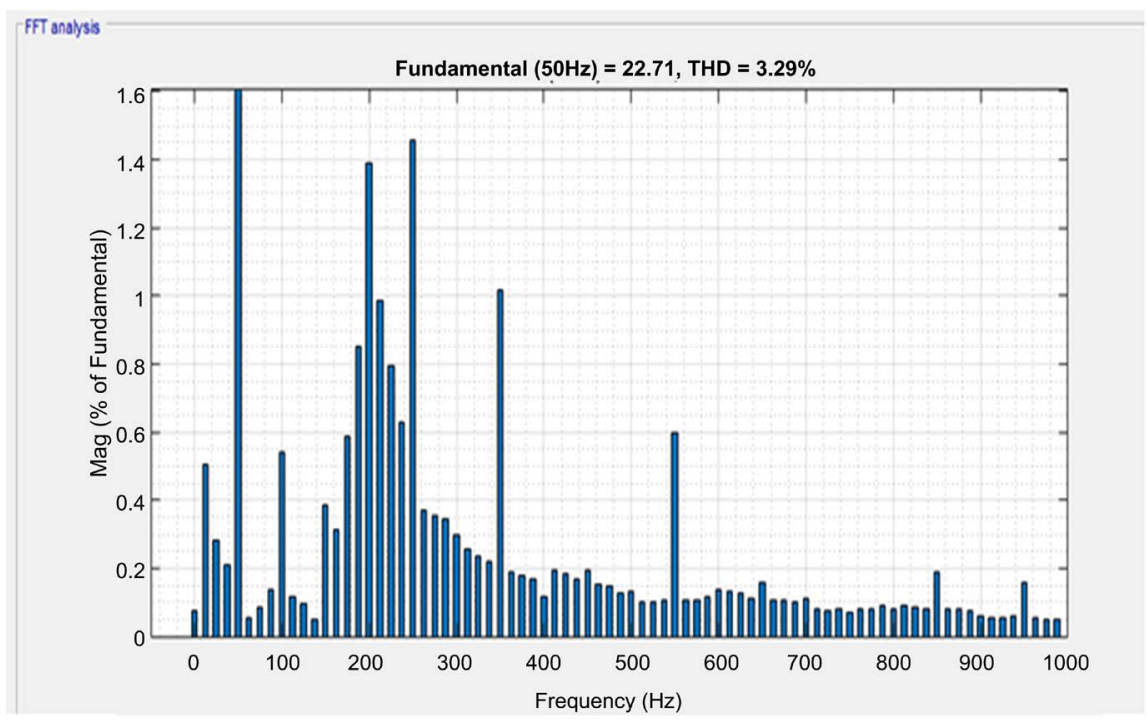

(b) 


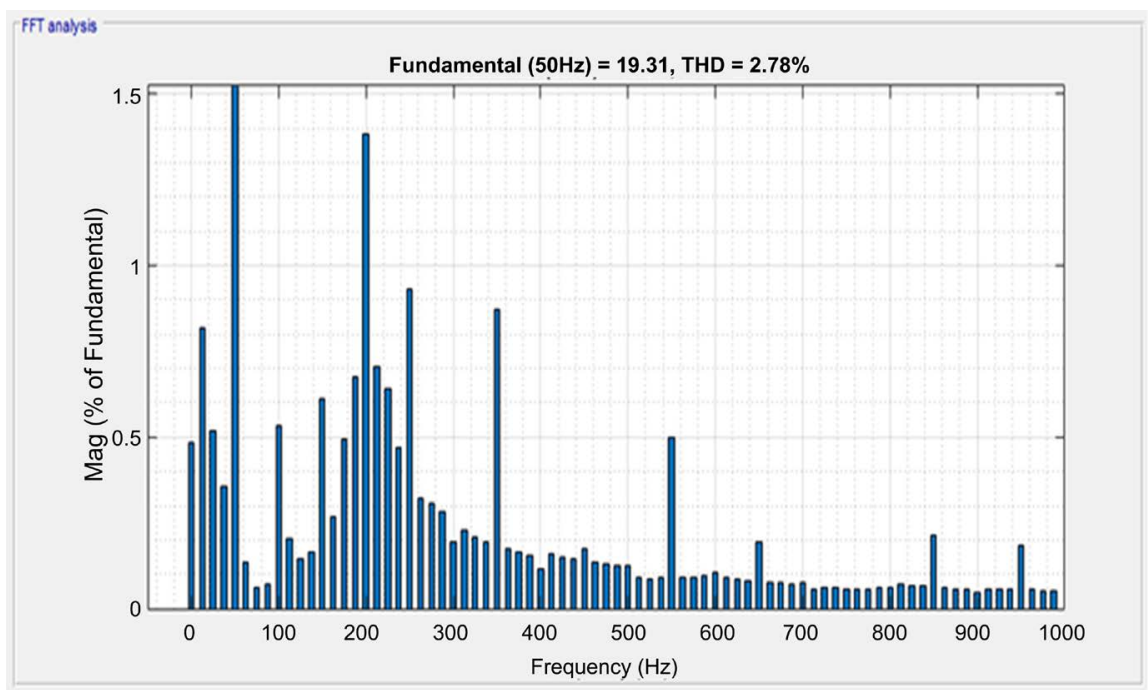

(c)

Figure 18. Harmonic THD by phase. (a) THD Phase 1; (b) THD Phase 2; (c) THD Phase 3.

\subsection{Case of an Unbalance Non-Linear Load after Filtering}

In the case of an unbalanced non-linear load the simulation is done and observation is taken per phase since an additional non-linear load is added to each phase with different values causing each phase to obtain different THD. The table of values for the additional load is given in Table 6 below.

The h-infinity command here at this level allows the filter to produce harmonic currents adapted to the disturbance of the network depending on the nature of the disturbance of each phase with THD concerned of $1.8 \%, 3.29 \%$, $2.78 \%$.

\subsection{Comparative Study under Various Conditions}

A comparative study of the three phase source current THD during unbalanced and balanced load at various operating conditions is presented in Table 7. From these results it is clear that the proposed control strategy works better at almost all operating conditions and thus helps in improving the quality of electric power delivered to the end user.

\section{Conclusion}

In this article, it was a question of simultaneously using two aspects for the optimization of harmonic pollution control, namely an algorithm of the robust stochastic $\mathrm{H}$-infinite control which offers several possibilities of implementation for real cases with electrical networks having API modules-siemens. This algorithm offers compensation results for THDs admissible by standard IEC 61000-2-2 as an additional contribution. This control and command technique is directly tested on a TLC adaptive hybrid filter topology which offers advantages such as reduction of switching losses during the injection of currents into the network, 
Table 6. Unbalanced load.

\begin{tabular}{cc}
\hline & Unbalanced load \\
\hline Phase 1; load resistance & $26 \Omega$ \\
Load inductance & $90 \mathrm{mH}$ \\
Phase 2; load resistance & $15 \Omega$ \\
Load inductance & $100 \mathrm{mH}$ \\
Phase 3 load resistance & $30 \Omega$ \\
Load inductance & $85 \mathrm{mH}$ \\
\hline
\end{tabular}

Table 7. Comparative simulation results.

\begin{tabular}{cc}
\hline \multicolumn{2}{c}{ BEFORE FILTERING } \\
\hline NAME & THD \\
\hline linear load & $00 \%$ \\
Balanced nonlinear load & $30 \%$ \\
Unbalanced nonlinear load (phase 1) & $27.98 \%$ \\
Unbalanced nonlinear load (phase 2) & $22.34 \%$ \\
Unbalanced nonlinear load (phase 3) & $30.48 \%$ \\
\hline AFTER FILTERING & \\
\hline balanced nonlinear load & $3.16 \%$ \\
\hline unbalanced nonlinear load (phase 1) & $1.88 \%$ \\
unbalanced nonlinear load (phase 2) & $3.29 \%$ \\
\hline Unbalanced nonlinear load (phase 3) & $2.78 \%$ \\
\hline
\end{tabular}

limitation of resonance problems and above all low power consumption at the continuous bus level allowing us to obtain normal results from $105 \mathrm{~V}$. Compared to existing models in the literature which require $600 \mathrm{v}$ for the same performance, this article therefore simultaneously offers two essential contributions to the optimization of harmonic pollution control.

\section{Conflicts of Interest}

The authors declare no conflicts of interest regarding the publication of this paper.

\section{References}

[1] Santos, E., Khosravy, M. and Lima, M.A.A. (2020) Esprit Associated with Filter Bank for Power-Line Harmonics, Sub-Harmonics and Inter-Harmonics Parameters Estimation. Electrical Power and Energy Systems, 118, Article ID: 105731. https://doi.org/10.1016/j.ijepes.2019.105731

[2] Shivaie, M.A. (2019) Techno-Economic Multi-Objective Model for Hybrid Harmonic Filter Planning Considering Uncertainty in Non-Linear Loads. Electrical Power and Energy Systems, 112, 339-352. 
https://doi.org/10.1016/j.ijepes.2019.05.013

[3] Guan, M. (2020) Harmonics Detection via Input Observer with Grid Frequency Fluctuation. Electrical Power and Energy Systems, 115, Article ID: 105461.

https://doi.org/10.1016/j.ijepes.2019.105461

[4] Hanna Nohra, A.F., Kanaan, H.Y. and Fadel, M. (2016) Comparative Evaluation of Harmonic Compensation Methods Based on Power Calculation and Current Harmonic Detection for Single-Phase Applications. IECON 2016 42nd Annual Conference of the IEEE Industrial Electronics Society, Florence, 23-26 October 2016, 3685-3690.

[5] Marini, A., Ghazizadeh, M.-S. and Mortazavi, S.S. (2019) A Harmonic Power Market Framework for Compensation Management of DER Based Active Power Filters in Microgrids. Electrical Power and Energy Systems, 113, 916-931.

https://doi.org/10.1016/j.ijepes.2019.06.020

[6] Yang, L. (2020) 3D Modeling of an HVDC Converter Transformer and Its Application on the Electrical Field of Windings Subject to Voltage Harmonics. Electrical Power and Energy Systems, 117, Article ID: 105581.

https://doi.org/10.1016/j.ijepes.2019.105581

[7] Marini, A. and Piegari, L. (2019) A Harmonic Power Market Framework for Compensation Management of DER Based Active Power Filters in Microgrids. Electrical Power and Energy Systems, 113, 916-931. https://doi.org/10.1016/j.ijepes.2019.06.020

[8] Kapoor, R. (2011) Hybrid Demodulation Concept and Harmonic Analysis for Single/Multiple Power Quality Events Detection and Classification. Electrical Power and Energy Systems, 33, 1608-1622. https://doi.org/10.1016/j.ijepes.2011.06.006

[9] Jannesar, M.R. (2019) Optimal Probabilistic Planning of Passive Harmonic Filters in Distribution Networks with High Penetration of Photovoltaic Generation. Electrical Power and Energy Systems, 110, 332-348. https://doi.org/10.1016/j.ijepes.2019.03.025

[10] Padmanathan, K., Govindarajan, U., Ramachandaramurthy, V.K., Selvi, S.O.T. and Jeevarathinam, B. (2018) Integrating Solar Photovoltaic Energy Conversion Systems Intoindustrial and Commercial Electrical Energy Utilization-A Survey. Journal of Industrial Information Integration, 10, 39-54.

https://doi.org/10.1016/j.jii.2018.01.003

[11] Kalair, A., Abas, N., Kalair, A.R., Saleem, Z. and Khan, N. (2017) Review of Harmonic Analysis, Modeling and Mitigation Techniques. Renewable and Sustainable Energy Reviews, 78, 1152-1187. https://doi.org/10.1016/j.rser.2017.04.121

[12] Nduka, O.S. and Pal, B.C. (2018) Quantitative Evaluation of Actual Loss Reduction Benefits of a Renewable Heavy DG Distribution Network. IEEE Transactions on Sustainable Energy, 9, 1384-1396. https://doi.org/10.1109/TSTE.2017.2776610

[13] Hu, H., Shi, Q., He, Z., He, J. and Gao, S. (2015) Potential Harmonic Resonance Impacts of PV Inverter Filters on Distribution Systems. IEEE Transactions on Sustainable Energy, 6, 151-161. https://doi.org/10.1109/TSTE.2014.2352931

[14] Wang, S., Liu, X., Wang, K., Wu, L. and Zhang, Y. (2018) Tracing Harmonic Contributions of Multiple Distributed Generations in Distribution Systems with Uncertainty. International Journal of Electrical Power \& Energy Systems, 95, 585-591. https://doi.org/10.1016/j.ijepes.2017.09.014

[15] Kaddah, S.S., Abo-Al-Ez, Kh.M., Megahed, T.F. and Osman, M.G. (2016) Probabilistic Power Quality Indices for Electric Grids with Increased Penetration Level of Wind Power Generation. International Journal of Electrical Power \& Energy Sys- 
tems, 77, 50-58. https://doi.org/10.1016/j.ijepes.2015.09.026

[16] Wang, L. (2019) Adaptive Hybrid Active Power Filters. Power Systems Library of Congress Control Number: 2018948613, Springer, Singapore.

[17] Dugan, R.C., McGranaghan, M.F., Santoso, S. and Beaty, H.W. (2004) Applied Harmonics. In: Electrical Power Systems Quality, 2nd Edition, McGraw-Hill Education, New York, 225-294, Chapter 6.

[18] Akagi, H. (1996) New Trends in Active Filters for Power Conditioning. IEEE Transactions on Industry Applications, 32, 1312-1322. https://doi.org/10.1109/28.556633

[19] Hong, Y.Y., Chiu, C.S. and Huang, S.W. (2016) Multi-Scenario Passive Filter Planning in Factory Distribution System by Using Markov Model and Probabilistic Sugeno Fuzzy Reasoning. Applied Soft Computing, 41, 352-361. https://doi.org/10.1016/j.asoc.2016.01.015

[20] Sakar, S., Balci, M.E., Aleem, S.H.E.A. and Zobaa, A.F. (2018) Integration of Large-Scale PV Plants in Non-Sinusoidal Environments: Considerations on Hosting Capacity and Harmonic Distortion Limits. Renewable and Sustainable Energy Reviews, 82, 176-186. https://doi.org/10.1016/j.rser.2017.09.028

[21] Chen, Y.L. (2005) Optimal Multi-Objective Single-Tuned Harmonic Filter Planning. IEEE Transactions on Power Delivery, 20, 1191-1197. https://doi.org/10.1109/TPWRD.2002.844282

[22] Chang, Y.P. and Low, C. (2008) Optimization of a Passive Harmonic Filter Based on the Neural Genetic Algorithm with Fuzzy Logic for a Steel Manufacturing Plant. Expert Systems with Applications, 34, 2059-2070. https://doi.org/10.1016/j.eswa.2007.02.040

[23] Chang, Y.P. (2010) Integration of SQP and PSO for Optimal Planning of Harmonic Filters. Expert Systems with Applications, 37, 2522-2530. https://doi.org/10.1016/j.eswa.2009.08.025

[24] Chang, G.W., Chu, S.Y. and Wang, H.L. (2006) A New Method of Passive Harmonic Filter Planning for Controlling Voltage Distortion in a Power System. IEEE Transactions on Power Delivery, 21, 305-312. https://doi.org/10.1109/TPWRD.2005.852355

[25] Mohammadi, M. (2015) Bacterial Foraging Optimization and Adaptive Version for Economically Optimum Sitting, Sizing and Harmonic Tuning Orders Setting of LC Harmonic Passive Power Filters in Radial Distribution Systems with Linear and Nonlinear Loads. Applied Soft Computing, 29, 345-356.

https://doi.org/10.1016/j.asoc.2015.01.021 


\section{Annex}

\section{Annex 1: Matlap Verification Compilation for $\mathrm{H}$-Infinity Corrector}

\%on detruit tout ce qui est present avant de commencer

clc

clear all

close all

$\mathrm{A}=\left[724.838^{\star} 10^{\wedge} 3314-2000 ;-314724.838^{\star} 10^{\wedge} 30-200 ; 666.700\right.$ 314; 0666.7

$-3140]$;

$\mathrm{B}=[00 ; 00 ;-666.70 ; 0-666.7]$;

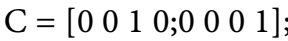

Dyw $=[10 ; 01]$;

$\mathrm{Dzu}=\left[\begin{array}{lll}1 & 0 ; 0 & 1\end{array}\right]$

$\mathrm{mu}=[10 ; 01]$;

py $=[10 ; 01]$;

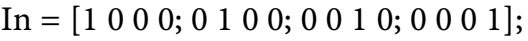

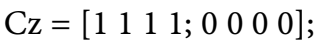

$\mathrm{Bw}=[10 ; 10 ; 10 ; 10]$;

$\%$ model d'etat

$\% \mathrm{x} .=\mathrm{Ax}+\mathrm{BwW}+\mathrm{BuU}$

$\% z=\mathrm{Cz}+\mathrm{DzwW}+\mathrm{DzuU}$

$\% \mathrm{y}=\mathrm{Cy}+\mathrm{DywW}+\mathrm{DyuU}$

$\%$ creation du systeme d'etat

$\mathrm{G}=\operatorname{ss}(\mathrm{A}, \mathrm{B}, \mathrm{C}, 0)$;

\%I) Commande Robuste $\mathrm{H}$ infinie

\% 1) matrice de commandabilité

$\% \mathrm{Co}=\left[\mathrm{B}, \mathrm{A}^{\star} \mathrm{B}, \mathrm{A}^{\wedge} 2^{\star} \mathrm{B}, \mathrm{A}^{\wedge} 3^{*} \mathrm{~B}\right]$

disp('matrice de commandabilite')

$\operatorname{ctrb}(\mathrm{G})$

\%rang de Co et dire si le systeme est commandable ou pas

$\%$ rang de matrice Co

$\% \mathrm{Co}=\operatorname{rank}\left(\left[\mathrm{B}, \mathrm{A}^{\star} \mathrm{B}, \mathrm{A}^{\wedge} 2^{\star} \mathrm{B}, \mathrm{A}^{\wedge} 3^{\star} \mathrm{B}\right]\right)$

$\mathrm{G}=\mathrm{ss}(\mathrm{A}, \mathrm{B}, \mathrm{C}, 0)$;

$\operatorname{disp}($ 'rang')

$\operatorname{rank}\left(\left[\mathrm{B}, \mathrm{A}^{\star} \mathrm{B}, \mathrm{A}^{\wedge} 2^{\star} \mathrm{B}, \mathrm{A}^{\wedge} 3^{*} \mathrm{~B}\right]\right)$ 
disp('analyse commandabilite')

if $(\operatorname{rank}(\operatorname{ctrb}(G))==\operatorname{rank}(A))$

'Le Syst est commandable'

else

'la matrice n-est pas commandable'

end

\%notre systeme est donc commandable

\%2) matrice d'observabilite.

$\% \mathrm{Ob}=\left[\mathrm{C} \mathrm{C}^{\star} \mathrm{A} \mathrm{C}^{\star} \mathrm{A}^{\wedge} 2 \mathrm{C}^{\star} \mathrm{A}^{\wedge} 3\right]$

disp('matrice observabilite')

$\operatorname{obsv}(\mathrm{G})$

$\operatorname{disp}($ 'rang')

$\operatorname{rank}\left(\left[C, C^{\star} A, C^{\star} A^{\wedge} 2, C^{\star} A^{\wedge} 3\right]\right)$

disp('analyse observabilite')

if $(\operatorname{rank}(\operatorname{obsv}(\mathrm{G}))==\operatorname{rank}(\mathrm{A}))$

'Le Syst est observable'

else

'la matrice n-est pas observable'

end

\%notre systeme est donc observable

$\%$ hypothese 2

disp('rang Dzu')

$\operatorname{rank}([\mathrm{Dzu}])$

$\operatorname{disp}($ 'rang $m u ')$

$\operatorname{rank}([\mathrm{mu}])$

if $(\operatorname{rank}(\mathrm{Dzu})==\operatorname{rank}(\mathrm{mu}))$

'il ya au moins autant de sorties commandees que entrees'

else

'il ya pas autant de sorties commandees que entrees'

end

$\operatorname{disp}($ 'rang Dyw')

$\operatorname{rank}([\mathrm{Dyw}])$

$\operatorname{disp}($ 'rang py') 
$\operatorname{rank}([\mathrm{py}])$

if $(\operatorname{rank}(D y w)==\operatorname{rank}(p y))$

'il ya au moins autant de entrees de criteres que de mesure '

else

'il ya pas autant de entrees de criteres que de mesure'

end

$\%$ hypothese 3

$\operatorname{disp}($ 'rang A + mu')

$\operatorname{disp}(' A$ ')

$\mathrm{F}=\left[\mathrm{A}-\mathrm{j}^{\star} \operatorname{In} \mathrm{B} ; \mathrm{Cz} \mathrm{Dzu}\right]$;

$\operatorname{rank}([\mathrm{A}])$

$\operatorname{disp}\left(\right.$ 'rang $\left.r 1^{\prime}\right)$

$\mathrm{r} 1=\operatorname{rank}([\mathrm{A}])+\operatorname{rank}([\mathrm{mu}])$

$\operatorname{disp}($ 'rang r2')

$\mathrm{r} 2=\operatorname{rank}([\mathrm{F}])$

if $(\operatorname{rank}(\mathrm{r} 1)==\operatorname{rank}(\mathrm{r} 2))$

'le transfert pzu na pas de zero sur laxe imaginaire '

else

'le transfert pzu a de zero sur laxe imaginair'

end

$\%$ hypothese 4

$\operatorname{disp}($ 'rang A + py')

$\operatorname{disp}(' A$ ')

$\mathrm{F} 1=\left[\mathrm{A}-\mathrm{j}^{\star} \operatorname{In} \mathrm{Bw} ; \mathrm{C} \mathrm{Dyw}\right]$;

$\operatorname{rank}([\mathrm{A}])$

$\operatorname{disp}($ 'rang $r 11$ ')

$\mathrm{r} 11=\operatorname{rank}([\mathrm{A}])+\operatorname{rank}([\mathrm{py}])$

disp('rang r12')

$\mathrm{r} 12=\operatorname{rank}([\mathrm{F} 1])$

if $(\operatorname{rank}(\mathrm{r} 11)==\operatorname{rank}(\mathrm{r} 12))$

'le transfert pyw na pas de zero sur laxe imaginaire '

else

'le transfert pyw a de zero sur laxe imaginair'

end

$\%$ les 4 hypotheses sont respectees alors il existe un correcteur $\mathrm{K}(\mathrm{p})$

$\%$ solution du probleme $\mathrm{H}$ infini standard

\%1) la matrice hamiltonienne 


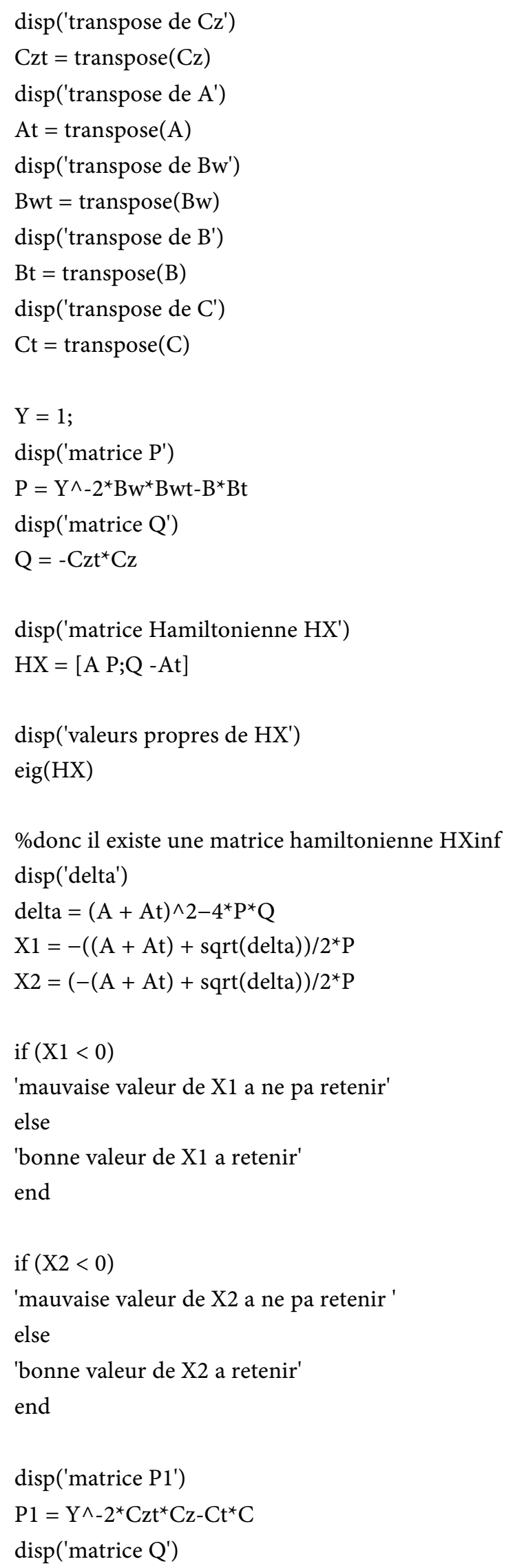


$\mathrm{Q} 1=-\mathrm{Bw}^{\star} \mathrm{Bwt}$

disp('matrice Hamiltonienne $\mathrm{HY}^{\prime}$ )

$\mathrm{HY}=[$ At $\mathrm{P} 1 ; \mathrm{Q} 1-\mathrm{A}]$

disp('valeurs propres de $\mathrm{HY}^{\prime}$ )

eig(HY)

\%donc il existe une matrice hamiltonienne HXinf

$\operatorname{disp}($ 'delta1')

delta $1=(\text { At }+\mathrm{A})^{\wedge} 2-4^{\star} \mathrm{P} 1^{\star} \mathrm{Q} 1$

$\mathrm{Y} 1=-((\mathrm{At}+\mathrm{A})+\operatorname{sqrt}(\operatorname{delta} 1)) / 2^{\star} \mathrm{P} 1$

$\mathrm{Y} 2=(-(\mathrm{At}+\mathrm{A})+\operatorname{sqrt}($ delta 1$)) / 2^{\star} \mathrm{P} 1$

if $(\mathrm{Y} 1<0)$

' mauvaise valeur de Y1 a ne pa retenir'

else

'bonne valeur de $\mathrm{Y} 1$ a retenir'

end

if $(\mathrm{Y} 2<0)$

'mauvaise valeur de Y2 a ne pa retenir '

else

'bonne valeur de Y2 a retenir'

end

\% 3 ) montrons que fi $\left(\mathrm{X} 2^{\star} \mathrm{Y} 2\right)<\mathrm{Y}^{\wedge} 2$

$\operatorname{disp}\left(' \mathrm{fi}\left(\mathrm{X} 2^{\star} \mathrm{Y} 2\right)\right.$ ')

$\mathrm{fi}=\mathrm{X} 2^{*} \mathrm{Y} 2$

if $\left(\mathrm{fi}<\mathrm{Y}^{\wedge} 2\right)$

'cest bon'

else

'cest mauvais"

end

$\%$ 4) determinons les parametres du correcteur central

$\operatorname{disp}($ 'Linf $)$

Linf $=-\mathrm{Y} 2^{\star} \mathrm{Ct}$

$\operatorname{disp}($ 'Finf')

Finf $=-\mathrm{Bt}^{\star} \mathrm{X} 2$ 


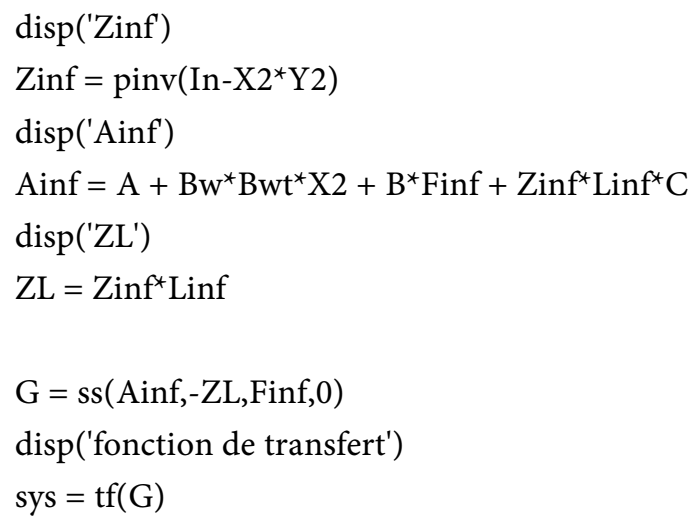

Annex 2: PLL (Phase Locked Loop)

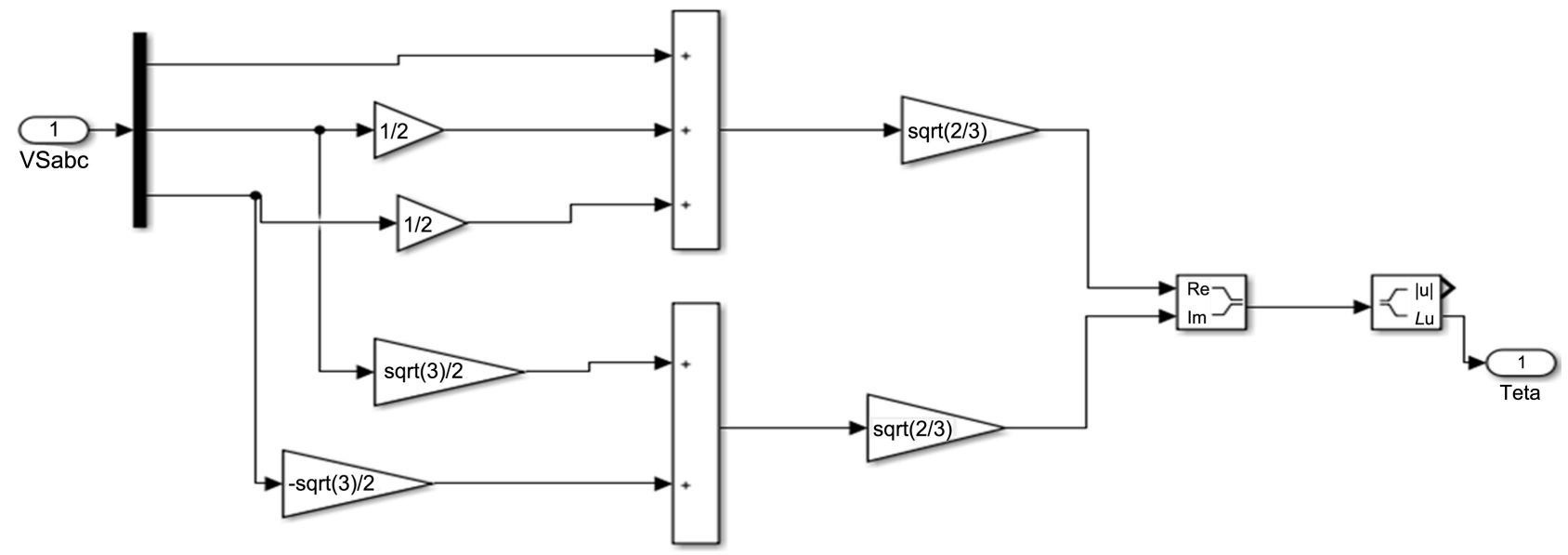

Annex 3: Transformation de Park

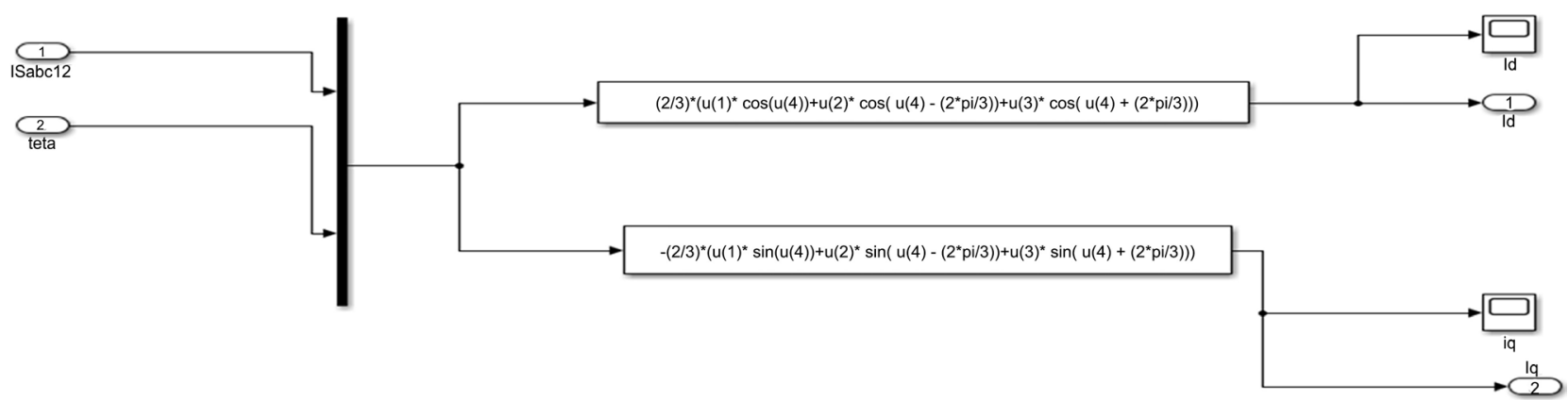


Annex 4: Transformation Inverse de Park

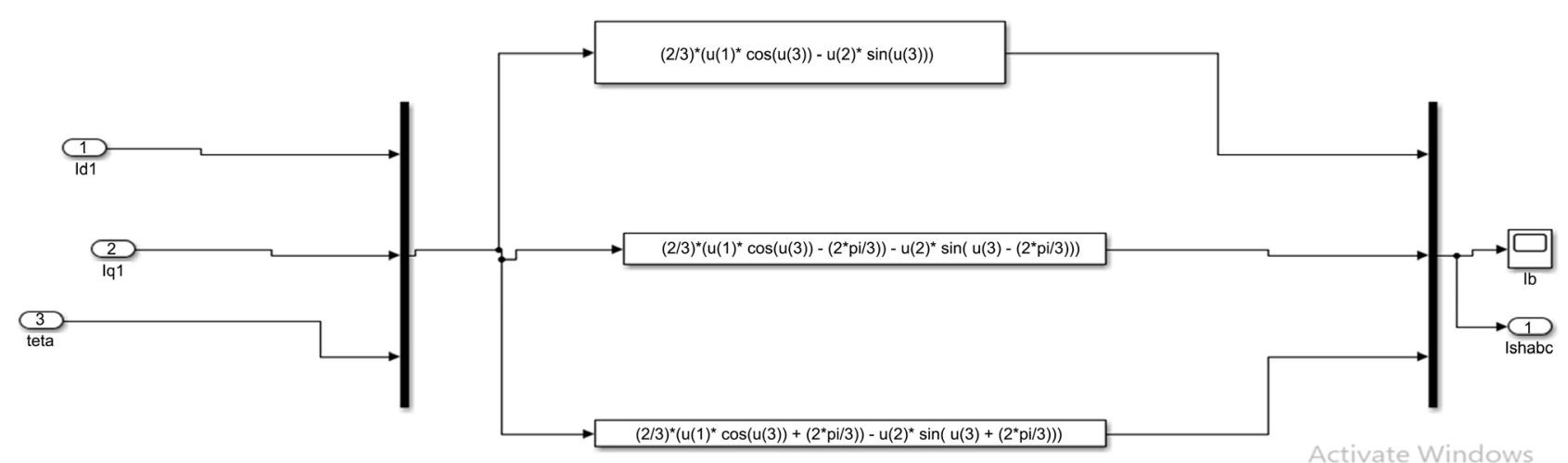

Annex 5: Subsystem

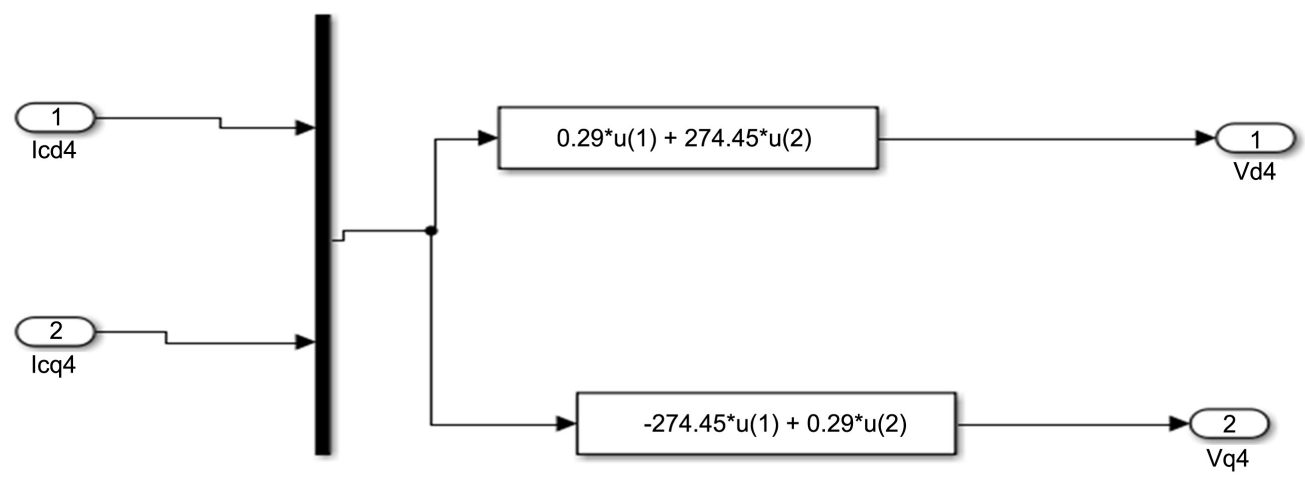

Annex 6: PI Corrector

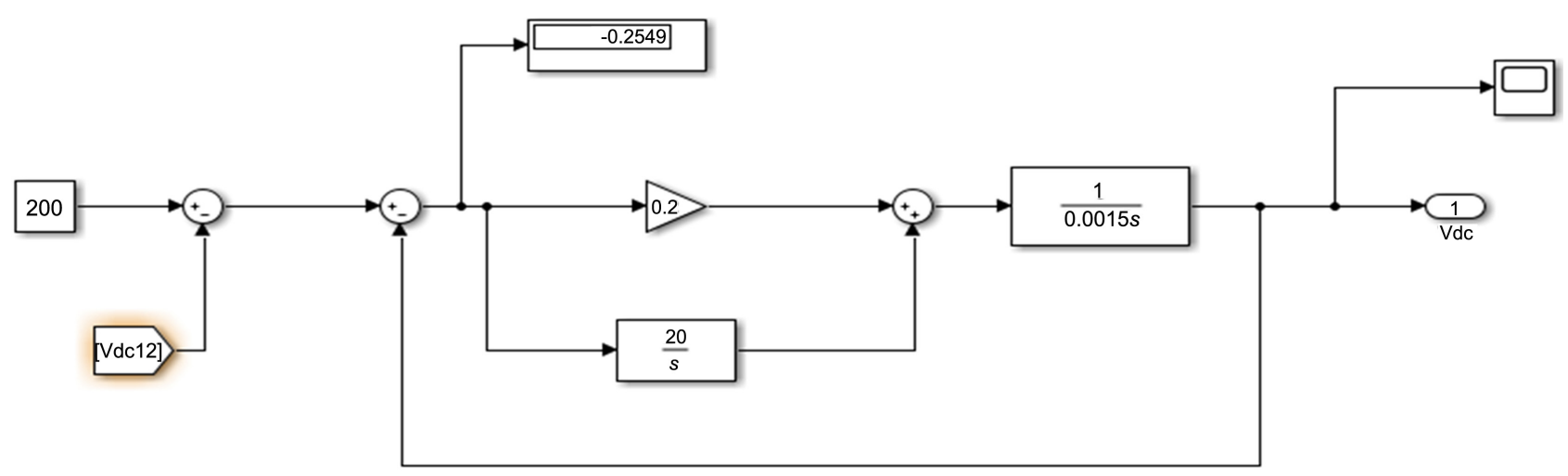




\section{Annex 7: Command H-Infinity}

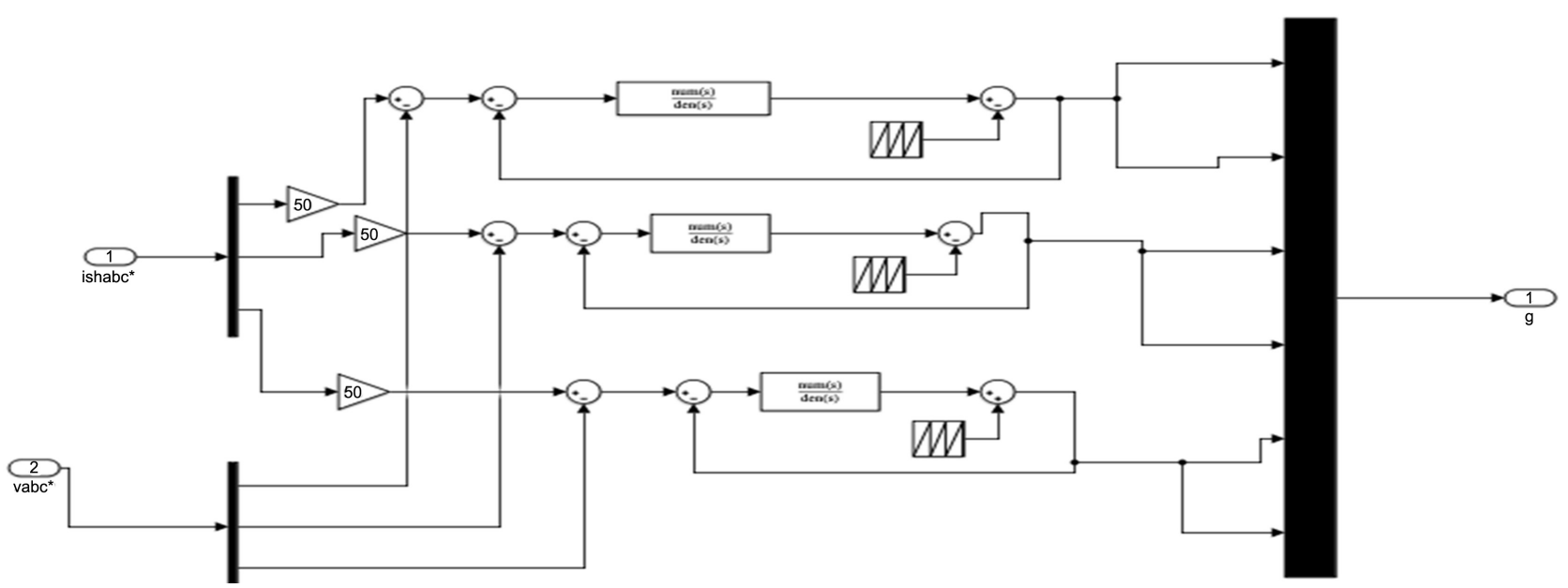

